\title{
High-resolution three-dimensional simulations of mid-ocean ridge hydrothermal systems
}

\section{Journal Article}

\section{Author(s):}

Coumou, Dim; Driesner, Thomas; Geiger, Sebastian; Paluszny, Adriana; Heinrich, Christoph A. (D)

Publication date:

2009-07-18

Permanent link:

https://doi.org/10.3929/ethz-b-000157493

Rights / license:

In Copyright - Non-Commercial Use Permitted

Originally published in:

Journal of Geophysical Research: Solid Earth 114, https://doi.org/10.1029/2008JB006121 


\title{
High-resolution three-dimensional simulations of mid-ocean ridge hydrothermal systems
}

\author{
D. Coumou, ${ }^{1}$ T. Driesner, ${ }^{1}$ S. Geiger, ${ }^{2}$ A. Paluszny, ${ }^{3}$ and C. A. Heinrich ${ }^{1}$ \\ Received 29 September 2008; revised 30 March 2009; accepted 22 April 2009; published 18 July 2009.
}

[1] High-resolution numerical simulations give clear insights into the three-dimensional structure of thermal convection associated with black-smoker hydrothermal systems. We present a series of simulations that show that, at heat fluxes expected at mid-ocean ridge spreading axes, upflow is focused in circular, pipe-like regions, with the bulk of the recharge taking place in the near-axial region. Recharging fluids have relatively warm temperatures. In this configuration, the system maximizes its heat output, which can be shown to be linked to nonlinearity in the fluid properties. Furthermore, we present a series of simulations with different permeability scenarios. These show that when permeability contrasts are moderate, convection maintains this pipe-like fluid flow structure. The permeability contrast has a dominant effect on flow patters only at early, immature, stages of convection, focussing upflow in high-permeability regions and downflow in low-permeability regions. In such early stages of convection, diffusive vent styles can emerge, which look remarkably similar to diffuse vent fields in natural systems. Finally, simulations in which permeability is defined as a function of temperature indicate that the brittle-ductile condition is likely to occur at temperatures not lower than $650^{\circ} \mathrm{C}$. At lower brittle-ductile transition temperatures, the system cannot remove the heat delivered from the magma chamber and vent temperatures are substantially lower than $400^{\circ} \mathrm{C}$. This result is in agreement with estimates of the brittle-ductile transition temperature from rock-mechanical studies and the occurrence of earthquakes in the oceanic lithosphere.

Citation: Coumou, D., T. Driesner, S. Geiger, A. Paluszny, and C. A. Heinrich (2009), High-resolution three-dimensional simulations of mid-ocean ridge hydrothermal systems, J. Geophys. Res., 114, B07104, doi:10.1029/2008JB006121.

\section{Introduction}

[2] Mid ocean ridge hydrothermal systems transport a significant part of the energy released by crystallization and cooling of the oceanic crust [Fisher, 2001]. Magmatic heat sources at depths of less than one to a few kilometers below the seafloor drive convection of seawater, with venting occurring at black-smoker fields located near the axial spreading center. Two key observations constrain the subseafloor thermal cell structure: (1) Measured venting temperatures are never substantially higher than $\sim 400^{\circ} \mathrm{C}[\mathrm{Jupp}$ and Schultz, 2000] and (2) venting occurs in focused regions (active black-smoker fields) separated by regions of inactivity [Lowell et al., 1995; Lowell and Germanovich, 2005]. The first observation is remarkable since inferred magmatic temperatures are around $1200^{\circ} \mathrm{C}$. The second observation has led to the suggestion that convection is

\footnotetext{
${ }^{1}$ Department of Earth Sciences, Institute of Isotope Geochemistry and Mineral Resources, ETH Zurich, Zurich, Switzerland.

${ }^{2}$ Institute of Petroleum Engineering, Heriot-Watt University, Edinburgh, UK.

${ }^{3}$ Department of Earth Science and Engineering, Imperial College London, London, UK.

Copyright 2009 by the American Geophysical Union. 0148-0227/09/2008JB006121\$09.00
}

mainly two-dimensional in the axial plane, so-called slot convection. In this paper, we argue that both observations can be explained by subseafloor three-dimensional convection cells operating at maximum energy transport.

[3] Early numerical studies of black-smoker systems used simplified fluid properties, with viscosity assumed constant and density varying linearly with temperature [Rosenberg et al., 1993; Cherkaoui and Wilcock, 1999; Schoofs and Hansen, 2000]. In addition to these simplified fluid properties, the fluid was often assumed to be incompressible, with density variations only accounted for in the buoyancy term (Boussinesq approximation). Although these studies contributed considerably to our understanding of fluid flow in the oceanic crust, other numerical studies showed that this approach is deficient when dealing with high-temperature convection systems [Straus and Schubert, 1977; Jupp and Schultz, 2000, 2004; Coumou et al., 2006].

[4] Some recent numerical studies included real fluid properties in their simulations which resulted in a number of important insights into the physics of black-smoker convection systems [Ingebritsen and Hayba, 1994; Jupp and Schultz, 2000, 2004; Coumou et al., 2006; Fontaine and Wilcock, 2007]. Ingebritsen and Hayba [1994] showed that convection cells operating near the critical point of water $\left(21 \mathrm{MPa}, 374^{\circ} \mathrm{C}\right)$ can transport energy much more rapidly than pure water convection cells operating at any other 


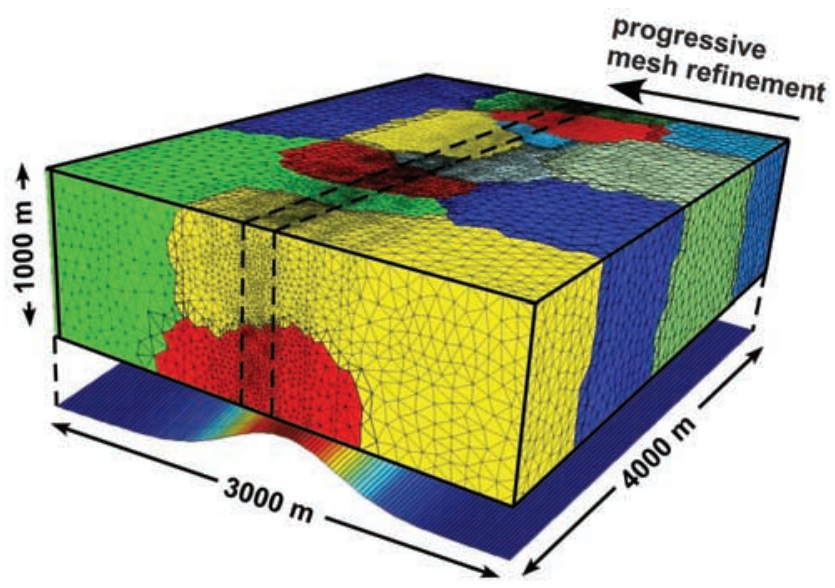

Figure 1. Three-dimensional mesh consisting of $2.5 \mathrm{M}$ tetrahedron elements (finest resolution between dashed lines). Resolution is refined toward the axial center and colors indicate computational domains assigned to separate processors. At the bottom boundary, the bell-shaped form of the heat flux profile is plotted.

pressure-temperature conditions. Seawater, in contrast to pure water, can undergo phase separation at higher than critical pressures which complicates the thermodynamics of black-smoker systems. It is clear, however, that most of them operate near the critical point of seawater of $29.8 \mathrm{MPa}$ and $407^{\circ} \mathrm{C}$, [Von Damm et al., 2003] and are therefore likely to be able to transport energy efficiently. Following up on these results, Jupp and Schultz [2000, 2004] argued that the nonlinear thermodynamics of water can explain why vent temperatures are close to $400^{\circ} \mathrm{C}$. In a recent paper, we showed that, in addition to realistic fluid properties, the usage of highresolution meshes and second-order accurate advection schemes is key to capturing the dynamical features of convection [Coumou et al., 2006]. At permeabilities exceeding $10^{-15} \mathrm{~m}^{2}$, convection is unstable, thermal plumes can split on their way to the seafloor and venting temperatures can oscillate on timescales ranging from years to centuries. Fontaine and Wilcock [2007] confirmed these dynamic features and pointed out that downflow areas can become relatively warm, commonly exceeding $150^{\circ} \mathrm{C}$.

[5] Realistic numerical studies in three-dimensional have been hampered by a lack of available computational power. Previous studies investigating three-dimensional hydrothermal convection at mid ocean ridges assumed incompressible fluids and low-permeability values $\left(<10^{-15} \mathrm{~m}^{2}\right.$ [i.e., Travis et al., 1991; Rabinowicz et al., 1998, 1999]), greatly reducing computational requirements. Rabinowicz et al. [1998] studied single phase fluid circulation, including nonlinearities in the fluid properties, at sediment hosted ridges where permeability is expected to be much lower than at more common unsedimented ridges. Higher permeabilities and the usage of compressible fluids can substantially increase computational requirements since, depending on the numerical method, computational timesteps can become very small. More problematic is the necessity to use high-resolution meshes when modeling high-permeability systems [i.e., Coumou et al., 2006]. To achieve the same resolution in threedimensional, the size of a mesh increases by 1 to 2 orders of magnitude compared to a two-dimensional mesh. This massive increase makes three-dimensional simulation of these systems, using standard single-processor numerical techniques, practically impossible.

[6] In this study, we use parallel computing techniques [Coumou et al., 2008c] to boost computational power to simulate hydrothermal convection in three-dimensional, using high-resolution meshes and real properties of compressible fluids. We present simulations of three-dimensional boxshaped models, consisting of several million elements, solved using 16 processors. In a previous paper [Coumou et al., 2008a] we showed that, for homogeneous permeability systems, convection in three-dimensional develops pipe-like upflow zones surrounded by narrow, relatively warm downflow zones. This configuration gives the highest heat output resulting from the nonlinearity in the fluid properties. In this paper, we extend these findings to heterogeneous permeability systems and investigate different heat flux and temperaturedependent permeability scenarios.

\section{Model Setup}

\subsection{Equation of State and Governing Equations}

[7] By assuming that the fluid is pure water and by taking pressures larger than the critical point of water $(22.1 \mathrm{MPa})$, we ensure that the fluid is in the single phase regime. This assumption substantially reduces the complexity of the problem, allowing the energy equation to be written into a temperature $(T)$ formulation [Geiger, 2004; Lowell and Germanovich, 2005; Coumou et al., 2006]:

$$
\left(\phi \rho_{f} c_{p f}+(1-\phi) \rho_{r} c_{p r}\right) \frac{\partial T}{\partial t}=\nabla k \nabla T-\nabla \cdot\left(\rho_{f} c_{p f} \mathbf{v} T\right) .
$$

Here $\phi$ is the porosity, $\mathbf{v}$ the Darcy velocity [Bear, 1972] and $\rho$ and $c_{p}$ stand for density and heat capacity respectively, with the subscripts $f$ and $r$ referring to fluid and rock. The pressure equation is solved decoupled from the energy equation, with the thermal expansion term entering as a source term into the pressure $(p)$ equation:

$$
\phi \rho_{f} \beta_{f} \frac{\partial p}{\partial t}=\nabla \cdot\left(\frac{k}{\mu_{f}}\left(\nabla p-\rho_{f} \mathbf{g}\right) \rho_{f}\right)+\phi \rho_{f} \alpha_{f} \frac{\partial T}{\partial t} .
$$

Here $\alpha_{f}$ is the fluid expansivity, $\beta_{f}$ its compressibility, $\mu_{f}$ its viscosity and $\mathbf{g}$ the gravitational acceleration. Properties of pure water at supercritical conditions vary nonlinearly and over several orders of magnitude with changing pressure and temperature. The fluid properties, $\rho_{f}, \mu_{f}, \alpha_{f}, \beta_{f}$ and $c_{p f}$ are obtained using lookup tables based upon the pure water equation of state by Haar et al. [1982]. Equations (1) and (2) are solved using a finite element-finite volume method (FE-FV), in which advective parts of the equations are solved using the finite volume method and diffusive parts using the finite element method. The exact details of this scheme have been described in previous publications [Geiger et al., 2004, 2006; Coumou et al., 2006].

\subsection{Model Dimensions}

[8] We solve equations (1) and (2) within a threedimensional, box-shaped domain extending $4 \mathrm{~km}$ in the along-axis direction and $3 \mathrm{~km}$ in the across-axis direction with a height of $1 \mathrm{~km}$ (Figure 1). We tested the validity of 
the $4 \mathrm{~km}$ along-axis dimension with a number of twodimensional along-axis simulations. These showed that if $\mathrm{k}>10^{-15} \mathrm{~m}^{2}$, the aspect ratio, i.e., the horizontal dimension divided by the vertical dimension of a single convection cell, becomes sufficiently small such that the vertical boundaries do not influence the solution. The axial plane is located in the center of the model, resulting in an off-axis extent of $1500 \mathrm{~m}$ in both directions. This should be sufficient since observed axial magma chambers typically have an across-axis dimension of $500 \mathrm{~m}$ on either side [Sinton and Detrick, 1992; Lowell and Germanovich, 2005].

\subsection{Discretization}

[9] The model domain is discretized using irregularly sized tetrahedron elements [Paluszny et al., 2007], with the resolution of the mesh increasing toward the axial center (Figure 1). To capture the true dynamics of transient thermal convection systems, high-resolution meshes and secondorder accurate transport schemes are required [Coumou et al., 2006; Fontaine and Wilcock, 2007]. Therefore we ensure that in the central region of our three-dimensional models, the resolution of the mesh is similar to the resolution found to be sufficiently fine in two-dimensional models described in [Coumou et al., 2006]. This implies node-tonode distances of roughly $20 \mathrm{~m}$. In the across-axis direction, the mesh-resolution is gradually relaxed, resulting in a mesh consisting of $2.5 \mathrm{M}$ tetrahedron elements. Figure 1 shows the partitioning of the global domain into 16 subdomains, each one assigned to a single processor. We employ parallel computing techniques as described in detail by Coumou et al. [2008c]. The use of this high-performance processing power was essential for calculating these simulations within an acceptable time frame. Typically, with 16 processors it took two weeks to calculate $\sim 150$ years of convection, whereas on a single processor, expected computation time would have been at least half a year.

\subsection{Boundary Conditions}

[10] The top boundary represents the seafloor at roughly $2.5 \mathrm{~km}$ water depth resulting in a constant pressure of $p=$ $25 \mathrm{MPa}$. Fluids are free to enter and leave the model via the top boundary, all other edges are no-flow boundaries. To allow hot fluids to vent, we use a mixed thermal boundary condition at the top. In elements along the top boundary experiencing upflow, the vertical temperature gradient is set to zero, while elements experiencing downflow take in $10^{\circ} \mathrm{C}$ water. At the bottom boundary, the system is heated by a fixed heat flux. This is physically more realistic than a constant-temperature boundary condition since the latter essentially assumes that an infinite amount of heat can be transported into the system. The total bottom heat flux is constrained by the amount of basalt that crystallizes and cools, which is directly dependent on the spreading rate. Such an estimate gives values ranging from 10 to $\sim 120 \mathrm{MW}$ per kilometer of ridge axis [Baker and Massoth, 1987; Ginster et al., 1994; Baker and Urabe, 1996; Fisher, 2001; Ramondenc et al., 2006]. However, estimates from individual vent fields and ridge segments indicate a much higher heat output of 100 s to 1000 s of MW [Fisher, 2001], implying that magma supply is episodic and local. We therefore decided to work with two heat fluxes: a moderate value of $75 \mathrm{MW} / \mathrm{km}$ and a high heat flux value of
$350 \mathrm{MW} / \mathrm{km}$. The $350 \mathrm{MW} / \mathrm{km}$ estimate best represents a localized high heat flux area (less than $10 \mathrm{~km}$ ) on a medium to fast spreading ridge such as the Main Endeavour Field on the Endeavour Segment of the Juan de Fuca Ridge and the $9^{\circ} 50^{\prime} \mathrm{N}$ and $13-18^{\circ} \mathrm{S}$ areas on the East Pacific Rise. The heat flux is delivered in a Gaussian profile to the bottom of our model domain with the peak at the axial center. The half-width of this function is set to $500 \mathrm{~m}$ which is roughly half the across-axial width of a typical magma chamber [i.e., Sinton and Detrick, 1992; Lowell and Germanovich, 2005] and the background heat flux is set to $1 \mathrm{~W} / \mathrm{m}^{2}$.

\section{Simulation Results}

\subsection{Constraining Permeability}

[11] A critical parameter for hydrologic simulations is the permeability of the rock. For the ocean floor, direct measurements by borehole packer range from $10^{-14}$ to $10^{-12} \mathrm{~m}^{2}$ at shallow depths (up to $500 \mathrm{~m}$ ) to much smaller values $\left(10^{-17} \mathrm{~m}^{2}\right)$ at deeper levels [Fisher, 1998]. Such experiments have only been performed off axis, however, due to technical complexities related to drilling fresh basaltic crust. Near-axial permeabilities have therefore typically been estimated using simple mathematical analysis where $\mathrm{k}$ is constrained to account for the high measured heat fluxes [Wilcock and McNabb, 1996; Lowell and Germanovich, 2005]. However, since these approaches rely on simplified fluid properties, which seriously underestimates the energy which can be transported by near-critical fluids [Straus and Schubert, 1977], they tend to overestimate the required permeability $\left(\mathrm{k} \sim 10^{-12} \mathrm{~m}^{2}\right)$. Recent two-dimensional simulations using realistic fluid properties [Fontaine and Wilcock, 2007; Coumou et al., 2008b] showed that high axial heat fluxes can already be transported at much more moderate permeability $\left(\mathrm{k} \sim 5 \times 10^{-14} \mathrm{~m}^{2}\right)$. Here we take a new approach to constrain $\mathrm{k}$ by assuming that (1) the depth of the magmatic-hydrothermal interface is constant at $1000 \mathrm{~m}$ and (2) temperatures in this region are close to $\sim 1200^{\circ} \mathrm{C}$. Seismic studies have identified low-velocity zones at $1-2 \mathrm{~km}$ below spreading centers, interpreted to be (partly) molten magmatic lenses, stretching over several kilometers alongaxis [Singh et al., 1998; Kent et al., 2000; Dunn et al., 2000]. Sufficiently high temperatures close to $1200^{\circ} \mathrm{C}$ are required to keep basalt at sufficiently high melt fraction to be imaged as a melt-lens reflector by seismic surveys [Sinton and Detrick, 1992; Singh et al., 1998]. The two defined criteria can, for a fixed heat flux, only be fulfilled within a narrow permeability range (L. M. Cathles, personal communication, 2007). At higher permeabilities the hydrothermal system will cool the bottom layer more efficiently, resulting in lower bottom temperatures. On the other hand, if permeability is too low, the systems cannot remove heat efficiently and bottom temperatures will rise to unrealistically high values. Figure 2 illustrates this principle in more detail, plotting the temperature at the bottom of the model for simulations using slightly different permeabilities with heat fluxes of $75 \mathrm{MW} / \mathrm{km}$ and $350 \mathrm{MW} / \mathrm{km}$. Figure $2 \mathrm{c}$ shows that, for a $350 \mathrm{MW} / \mathrm{km}$ heat flux and a permeability of $5 \times 10^{-14} \mathrm{~m}^{2}$, only a very few bottom nodes reach $1200^{\circ} \mathrm{C}$. When permeability is decreased by only a small factor, i.e., to $3 \times 10^{-14} \mathrm{~m}^{2}$, large areas appear where the temperature is $1200^{\circ} \mathrm{C}$ or higher (Figure 2d). Likewise, for the $75 \mathrm{MW} / \mathrm{km}$ models, a similar permeability 

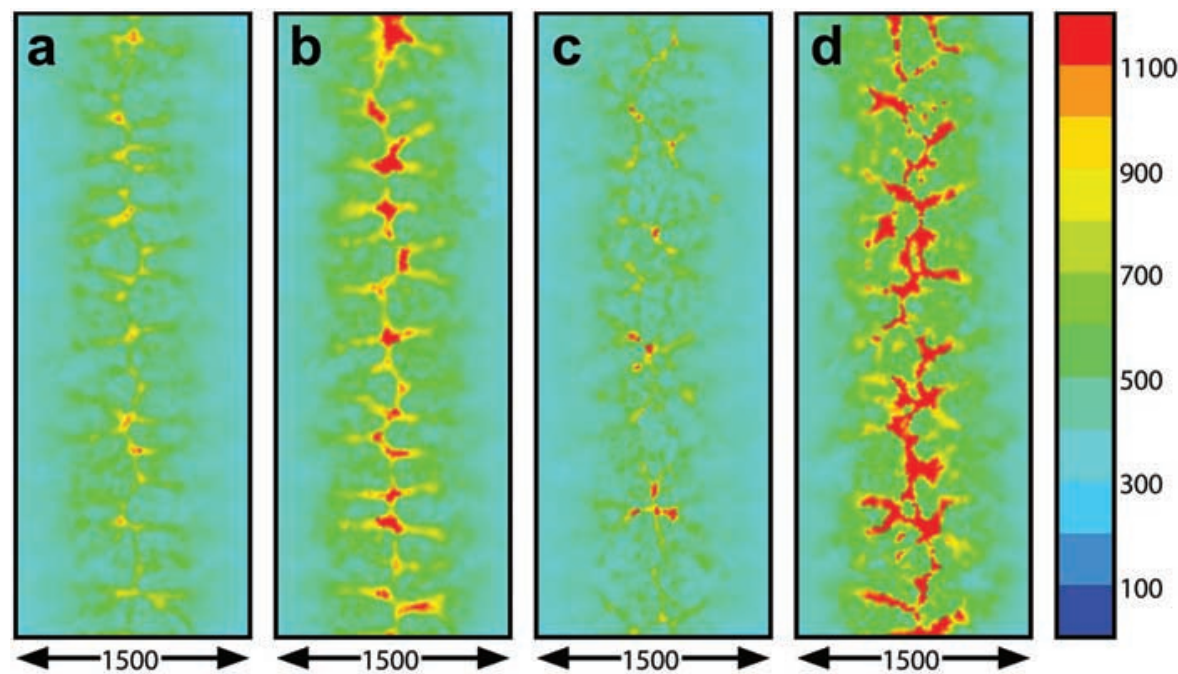

Figure 2. Bottom temperatures in the axial region for models with different (homogeneous) permeability-heat flux combinations: (a) $q=75 \mathrm{MW} \mathrm{km}{ }^{-1}$ and $k=1 \times 10^{-14} \mathrm{~m}^{2}$ after 660 years; (b) $q=75 \mathrm{MW} \mathrm{km}^{-1}$ and $k=0.75 \times 10^{-14} \mathrm{~m}^{2}$ after 660 years; (c) $q=350 \mathrm{MW} \mathrm{km}^{-1}$ and $k=5 \times 10^{-14} \mathrm{~m}^{2}$ after 150 years; and (d) $q=350 \mathrm{MW} \mathrm{km}^{-1}$ and $k=3 \times 10^{-14} \mathrm{~m}^{2}$ after 150 years.

range is observed, but permeabilities are smaller due to the lower heat flux applied (Figures $2 \mathrm{a}$ and $2 \mathrm{~b}$ ).

\subsection{Low Heat Flux}

[12] First, we investigate three-dimensional thermal convection at a relatively low heat flux value of $75 \mathrm{MW}$ per km of ridge axis. For a homogeneous permeability, $k=1.0 \times$ $10^{-14} \mathrm{~m}^{2}$, a near-steady state upflow region develops along the full length of the ridge (see Figures $3 a$ and $3 b$ ). Here upwelling fluids have a moderate temperature of $\sim 300^{\circ} \mathrm{C}$.
Fluid flow is dominantly across-axis, with recharge occurring away from the axis and discharge occurring along the full length of the axial center. Only if we increase $k$ in the near-axial region do separate vent areas develop (see Figures $3 \mathrm{c}$ and $3 \mathrm{~d}$ ). In this example, $k$ is increased by an order of magnitude within a $100 \mathrm{~m}$ wide corridor along the axis. At the bottom boundary, the highest temperatures are now reached at the edges of the high-permeability layer instead of at the axial center (see Figure 3c). Rapid fluid flow within the permeable layer cools the bottom boundary
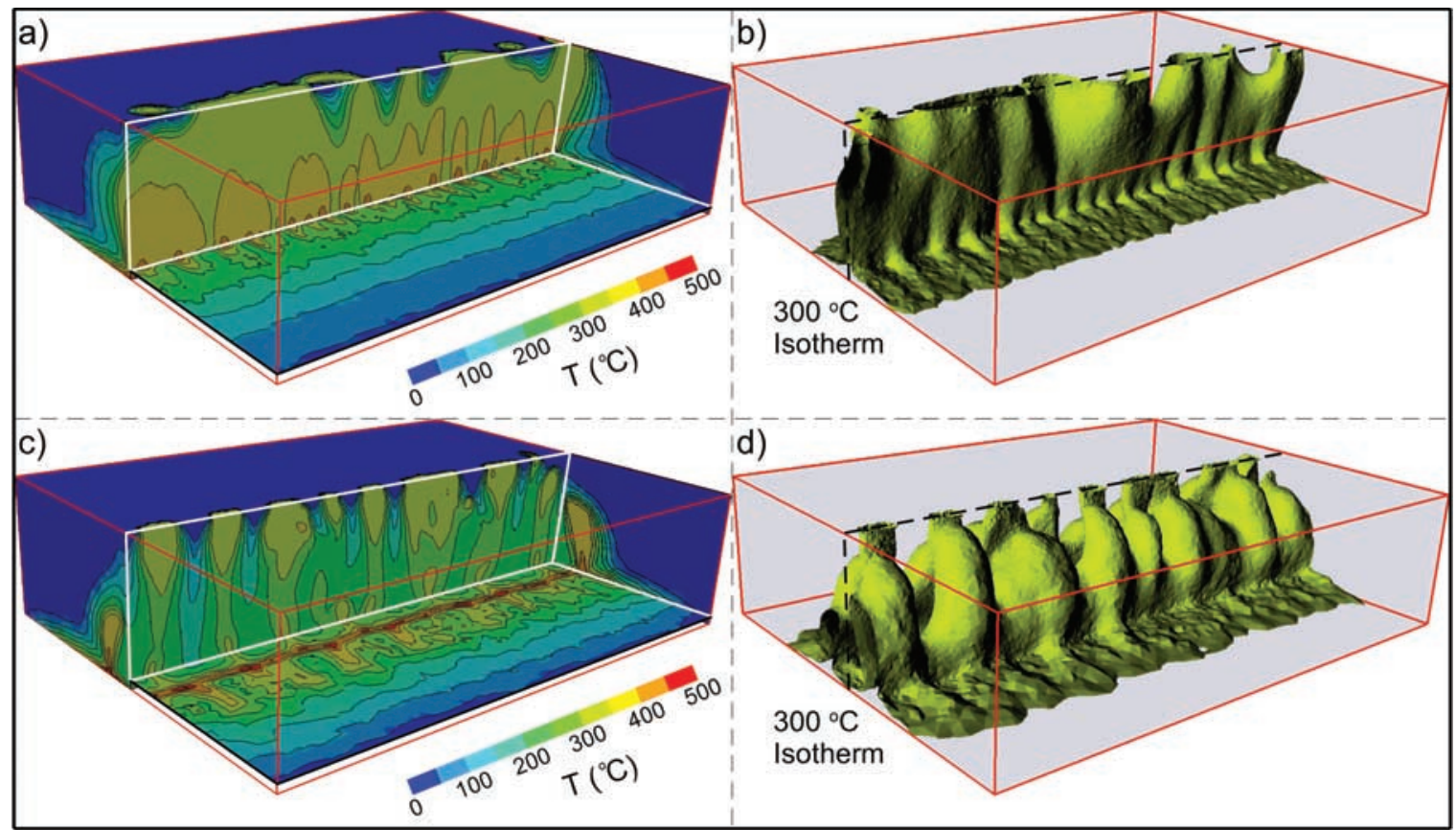

Figure 3. Thermal structure of simulations with a $75 \mathrm{MW} / \mathrm{km}$ heat flux. (a) Cross-sections, plotting isotherms every $50^{\circ} \mathrm{C}$, and (b) the $300^{\circ} \mathrm{C}$ isotherm for a simulation with $k=1.0 \times 10^{-14} \mathrm{~m}^{2}$ after 660 years. (c) and (d) plot the same quantities respectively for a simulation using a 100-m-thick axial plain having a permeability of $k=1.0 \times 10^{-13} \mathrm{~m}^{2}$ after 330 years. 


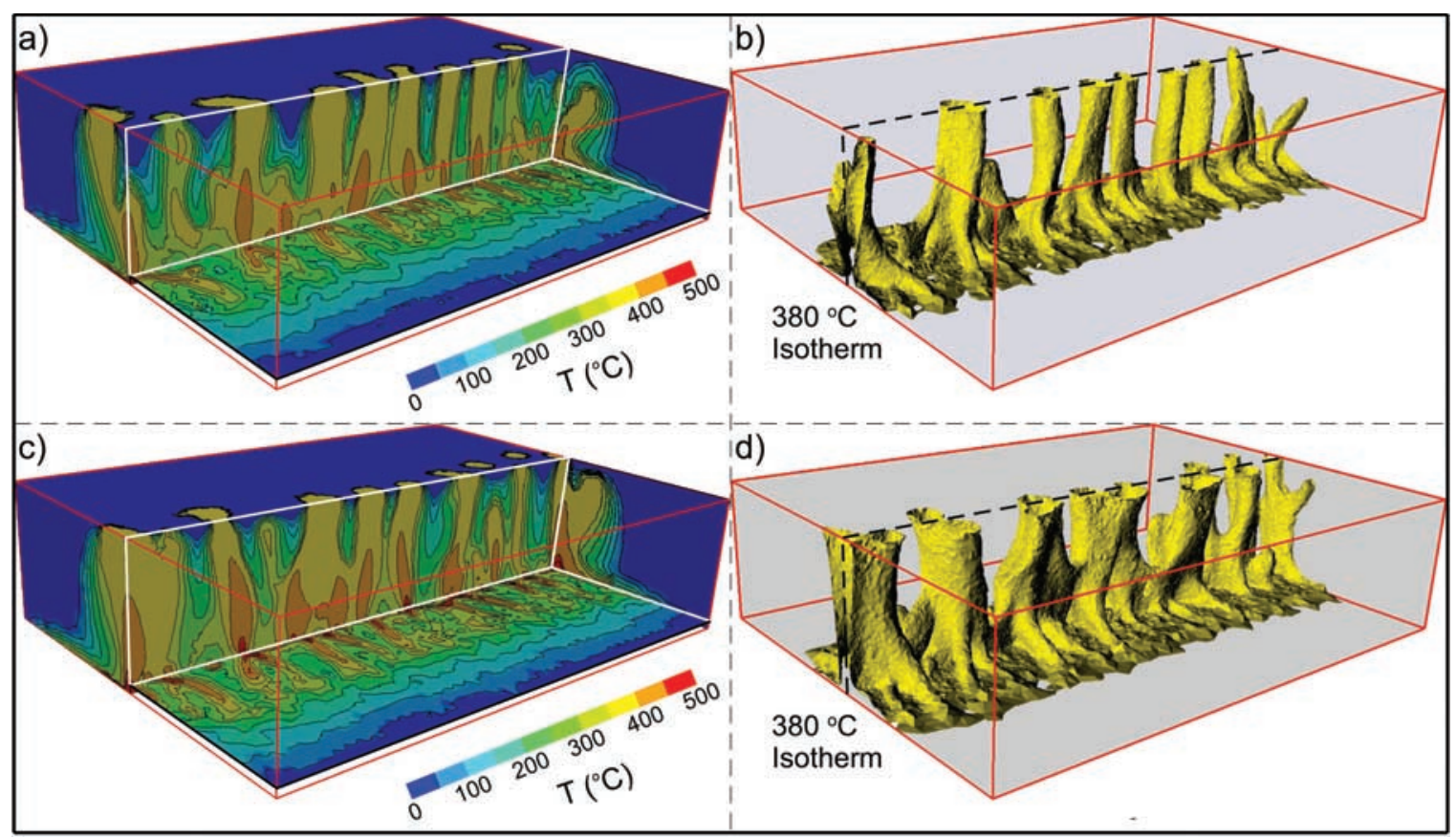

Figure 4. Thermal structure of homogeneous permeability simulations with a $350 \mathrm{MW} / \mathrm{km}$ heat flux after $\sim 120$ years. (a) Cross-sections plotting isotherms every $50^{\circ} \mathrm{C}$ and (b) the $380^{\circ} \mathrm{C}$ isotherm, both from a simulation with $k=5.0 \times 10^{-14} \mathrm{~m}^{2}$. (c) and (d) plot the same quantities for a simulation with $k=3.0 \times$ $10^{-14} \mathrm{~m}^{2}$.

much more efficiently, limiting the bottom-boundary temperatures in the near axial region. As a result, thermal plumes develop not at the axial center but slightly off-axis (see Figures 3c and 3d). Plumes merge close to the top boundary, resulting in regularly spaced discharge areas along the axial center with a spacing of $\sim 500 \mathrm{~m}$.

\subsection{High Heat Flux}

\subsubsection{Homogeneous Permeability}

[13] Figure 4 shows the thermal structure of simulations with a high heat flux $(350 \mathrm{MW} / \mathrm{km})$ with homogeneous permeabilities of respectively $3 \times 10^{-14} \mathrm{~m}^{2}$ and $5 \times$ $10^{-14} \mathrm{~m}^{2}$. Both simulations show that at these high heat flux conditions, upflow naturally forms into circular, nearvertical, pipelike regions. Thermal instabilities form away from the axis near the bottom boundary (Figures $4 \mathrm{a}$ and $4 \mathrm{c}$ ) and travel toward the main upflow regions at the axis. This results in subhorizontal tube-like structures in which hot fluids flow along the bottom boundary toward the axis (Figures $4 \mathrm{~b}$ and $4 \mathrm{~d}$ ). Adjacent to these features, cold fluid flows downward which is expressed in the rhythmic depressions of the isotherm in Figures $4 \mathrm{~b}$ and $4 \mathrm{~d}$. At the axis, the fluids reach temperatures of $\sim 400^{\circ} \mathrm{C}$ and move upward in circular, pipe-like discharge regions. At the top boundary, fluids discharge in regions with an average diameter of $\sim 250 \mathrm{~m}$. Although none of the high heat flux simulations reached a steady state, the location of the upflow zones remained constant throughout the lifetime of the simulation. Directly outside these upflow regions, fluids of moderate temperature flow downward at an increasing rate. This is explained in more detail in Figure 5, showing the vertical mass flux through horizontal cross-sections at different depths. Directly adjacent to the discharge areas, downflow through the top surface is maximized, as expressed by the dark blue regions in the left-hand plots of Figure 5. Further away from the axis, the magnitude of downflow decreases. The same pattern of increased downflow directly surrounding the upflowing regions, is observed in the horizontal cross-sections at $100 \mathrm{~m}, 500 \mathrm{~m}$ and $900 \mathrm{~m}$ depth. Fluids in these regions have temperatures between $100^{\circ} \mathrm{C}$ and $300^{\circ} \mathrm{C}$, as shown by the isotherms plotted in Figure 5 . The $300^{\circ} \mathrm{C}$ isotherm also more or less overlaps the white line separating up and down flowing regions, indicating that fluids of $300^{\circ} \mathrm{C}$ are close to neutral buoyancy. Figure 6 plots the average recharge through the top boundary of the two homogeneous permeability models as a function of off-axial distance, reflecting the increased recharge close to the axis.

\subsubsection{Heterogeneous Permeability}

[14] In addition to homogeneous permeability models, a series of simulations was done with different heterogeneous permeability structures. The permeability structure of these simulations as a function of off-axial distance is plotted in Figure 7. Figure 8 plots the thermal structures of these simulations when convection is fully evolved. With increasing average permeability values in the model, near bottom temperatures become lower, reflecting the more efficient removal of heat from the bottom. Upflow zones in the simulation using permeability model 1 , which has the largest average permeability, therefore become less hot and hardly reach $380^{\circ} \mathrm{C}$ (Figure $8 \mathrm{~b}$ ). In Figure 8 the permeability contrast increases from top to bottom, which results in the upflow zones becoming more and more aligned in the highpermeability region. Comparing Figures $8 \mathrm{e}$ and $8 \mathrm{f}$ (sharpest $k$-contrast) with Figures $4 \mathrm{c}$ and $4 \mathrm{~d}$ (no $k$-contrast) shows that the differences are limited. In the sharp $k$-contrast simulation upflow dominates in the high-permeability regions 


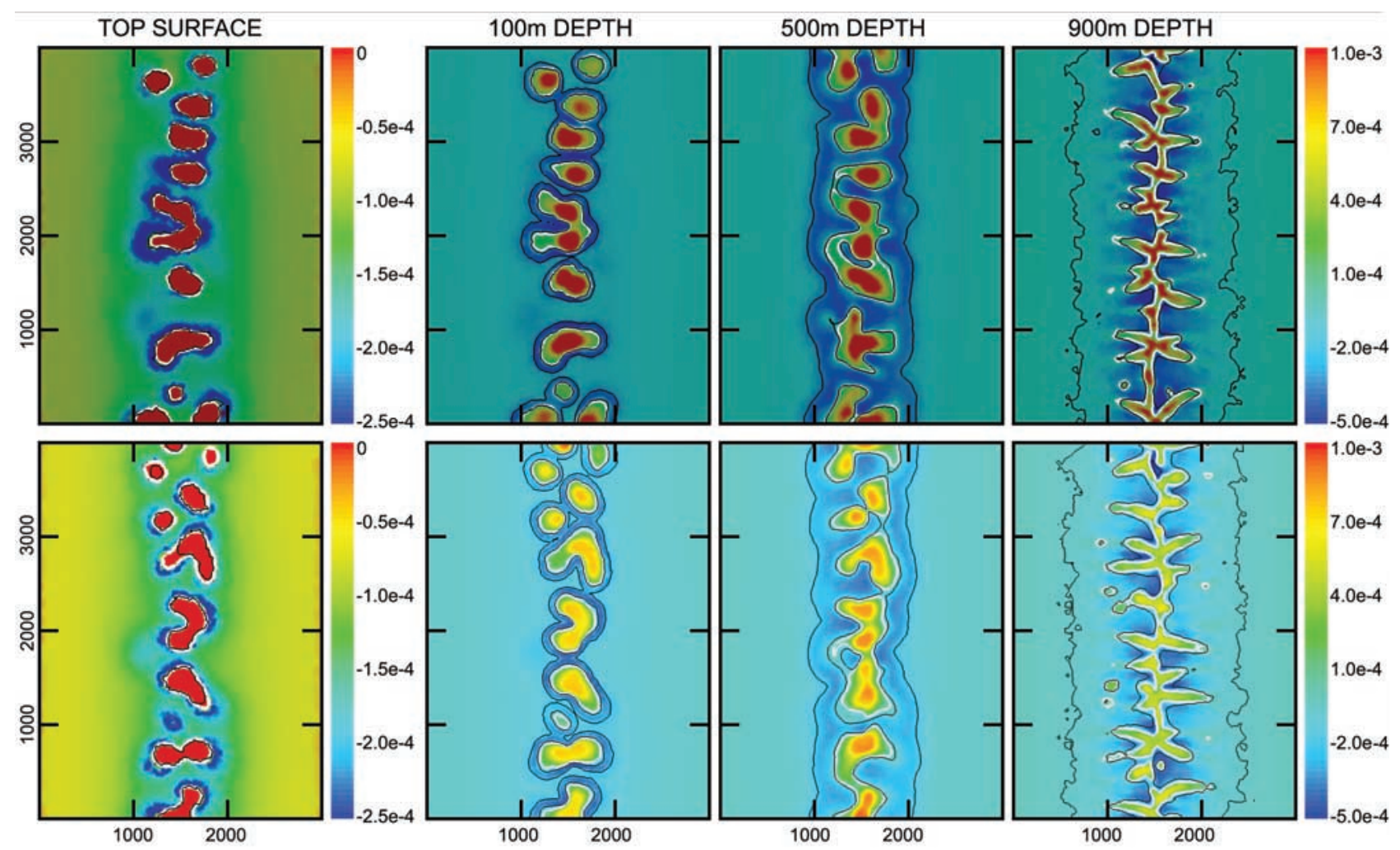

Figure 5. Recharge through the top and vertical mass fluxes $\left(\mathrm{kg} \mathrm{m}^{-2} \mathrm{~s}^{-1}\right)$ through horizontal sections at $100-\mathrm{m}, 500-\mathrm{m}$, and 900-m depth for homogeneous permeability models with a heat flux of $350 \mathrm{MW} / \mathrm{km}$ after $\sim 120$ years. The two black lines represent the $100^{\circ} \mathrm{C}$ and $300^{\circ} \mathrm{C}$ isotherms. (top) Pictures were generated using a permeability of $k=5.0 \times 10^{-14} \mathrm{~m}^{2}$; (bottom) pictures were generated using a permeability of $k=3.0 \times 10^{-14} \mathrm{~m}^{2}$. Note the difference in scale between pictures on the left and the rest.

resulting in venting occurring along more than half the distance of the axial spreading center. Apart from that, the typical pipe-like fluid flow structures are retained, which is also expressed in Figure 9. Figure 9 plots the mass flux

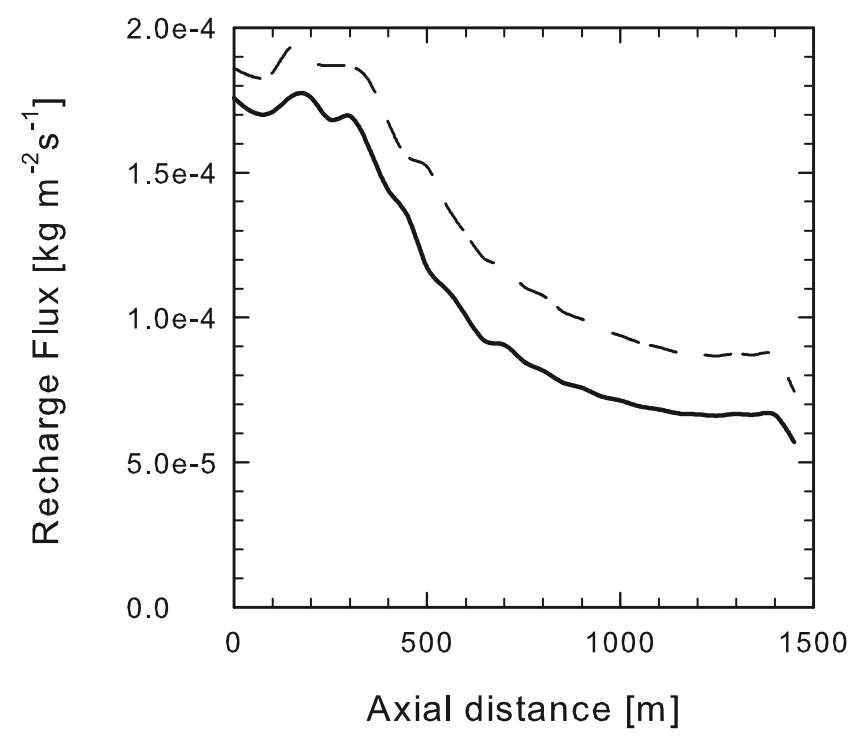

Figure 6. Average recharge $\left(\mathrm{kg} \mathrm{m}^{-2} \mathrm{~s}^{-1}\right)$ versus distance from the axis for homogeneous permeability models of $k=$ $3.0 \times 10^{-14} \mathrm{~m}^{2}$ (solid) and $k=5.0 \times 10^{-14} \mathrm{~m}^{2}$ (dashed). through horizontal cross-sections of models with an increased axial permeability when convection is fully developed. It shows that for moderate permeability contrasts, downward mass fluxes are maximized close to the axial plane, in regions where the downward flowing fluids are heated to temperatures of $100^{\circ} \mathrm{C}$ to $300^{\circ} \mathrm{C}$, just as in the homogeneous permeability cases. For progressively sharper permeability contrasts, upflow becomes more and more focused in the high-permeability plane, resulting in more

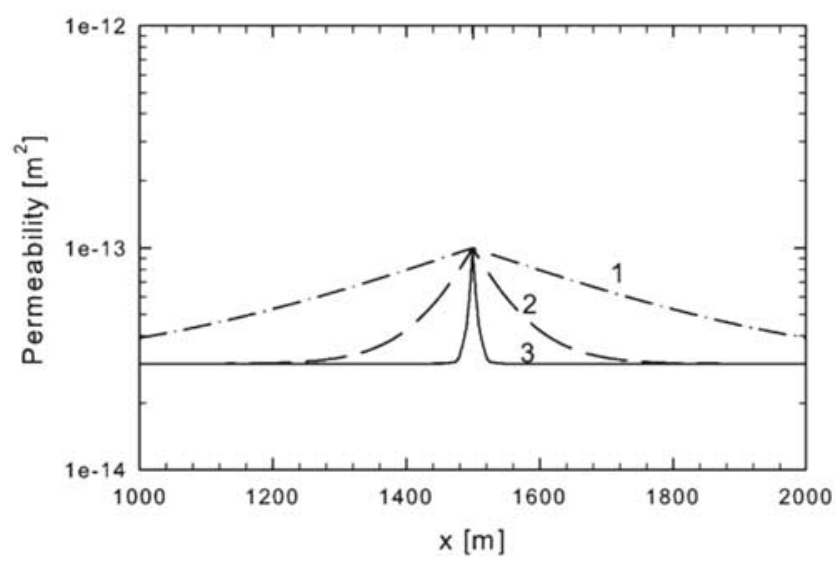

Figure 7. Investigated permeability models with an increased permeability toward the axis. 

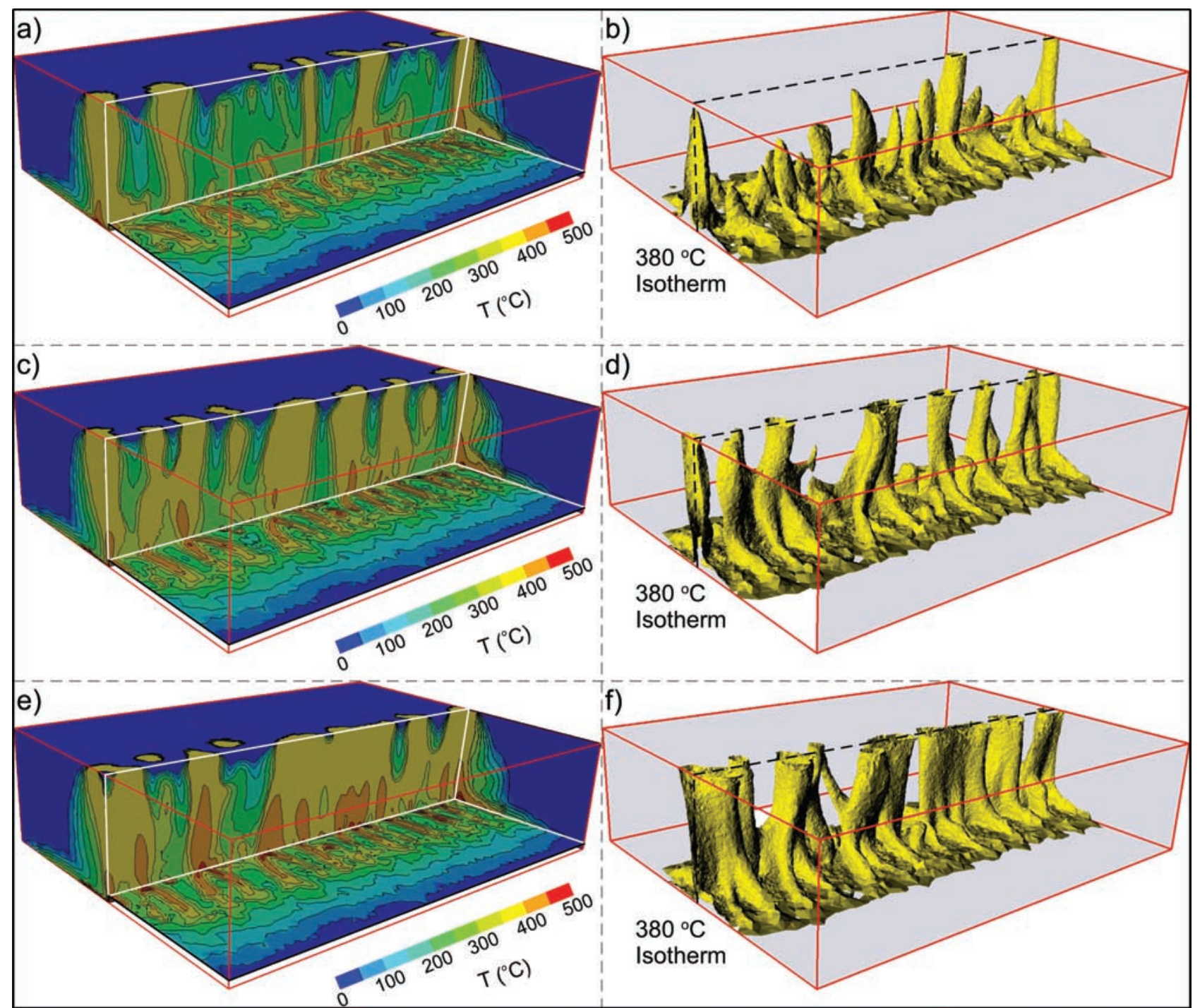

Figure 8. Thermal structure of heterogeneous permeability simulations. (a) Cross-sections plotting isotherms every $50^{\circ} \mathrm{C}$ and (b) the $380^{\circ} \mathrm{C}$ isotherm using permeability profile 1 (see Figure 7) after $\sim 120$ years. Same quantities plotted for, respectively permeability profile 2 (c and d) and profile 3 (e and f).

elongated discharge areas. This then results in recharge through the top as plotted in Figure 10 rather similar to homogeneous permeability models.

\subsubsection{Intermediate Convective Stage}

[15] So far, we have only described convection when it is fully evolved. The fully evolved state is reached after about $\sim 100$ years, depending on the exact permeability scenario used, and is characterized by downflow zones heated to temperatures around $\sim 200^{\circ} \mathrm{C}$. At early convective stages, downflow zones are still at ambient temperature and a different convective flow pattern can be discerned. Both up- and downflowing fluids are focused in the vertical highpermeability region, with upflowing fluids dominating in the upper section and downflowing fluids in the lower section (see Figure 11b). This style is characterized by large surface areas of low-temperature, low-volume flux venting surrounding and connecting smaller, circular areas of hightemperature, high-volume flux venting. This behavior is plotted in Figure 11c with low-temperature, diffusive style venting appearing in red. This snapshot in time occurs shortly after the first thermal plumes reach the top boundary of the model. This intermediate stage of convection was also observed in homogeneous permeability simulations, but was most prevalent in simulations with a high-permeable axial plane. Nevertheless, over time the red regions in Figure 11c become downflow zones and the typical convection style, as described in the previous sections, emerges. Still, the diffuse-venting state can remain active for several years. In section 5.3, we explain the physical reason for the occurrence of this state and show that it can explain some observations at natural systems.

\subsubsection{Temperature-Dependent $k$}

[16] Permeability in the oceanic crust is expected to be a function of temperature. The temperature range over which brittle rock becomes ductile is however poorly known. To investigate this, we perform a number of simulations with a temperature-dependent permeability and set the brittleductile transition progressively to higher temperatures. Sim- 

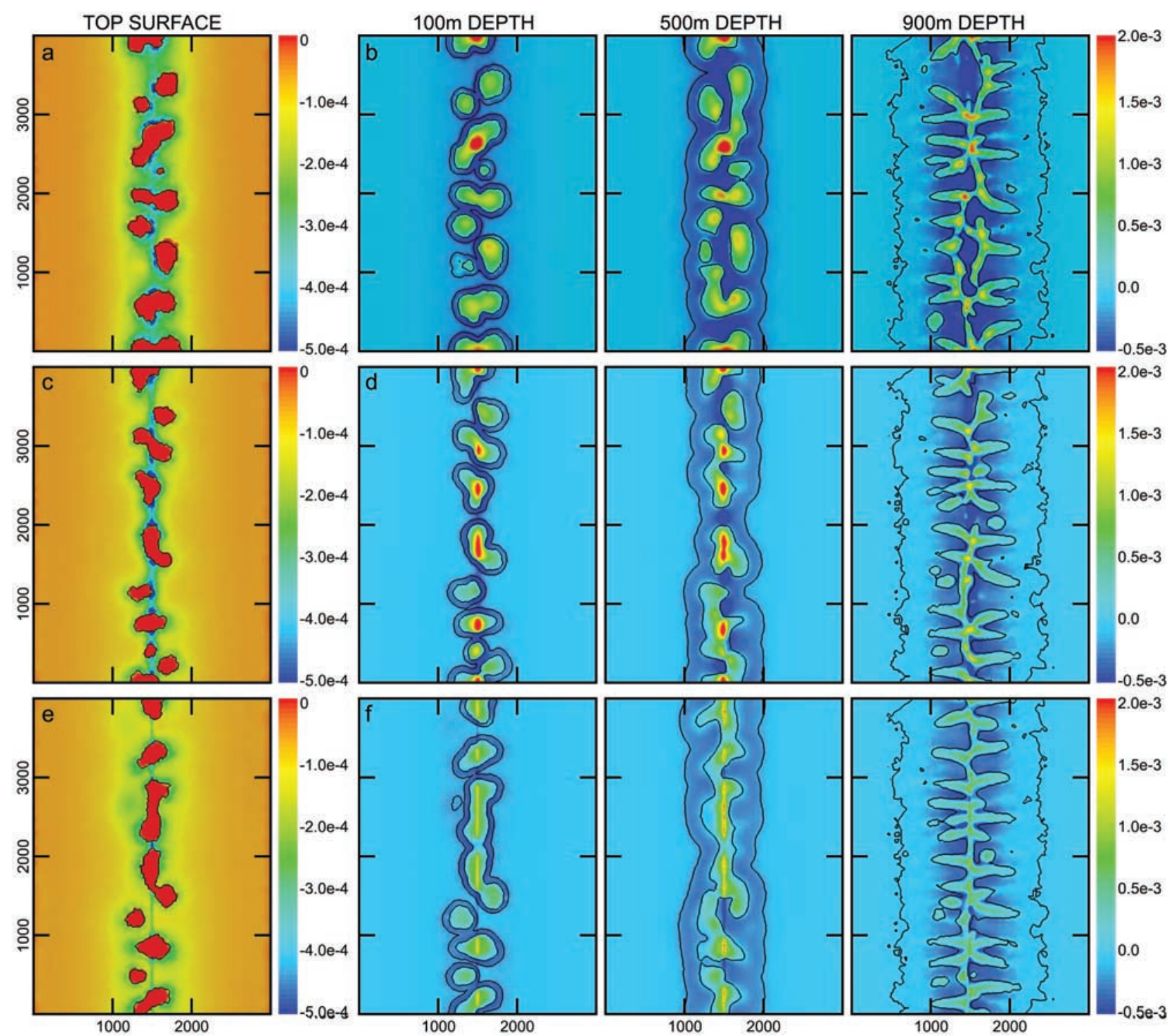

Figure 9. Recharge through the top and vertical mass fluxes $\left(\mathrm{kg} \mathrm{m}^{-2} \mathrm{~s}^{-1}\right)$ through horizontal sections at 100-m, 500-m, and 900-m depth, for heterogeneous permeability models. Using (top row) permeability profile 1 , (2nd row) permeability profile 2 , and ( 3 rd row) permeability profile 3 . All were generated at a simulation time of $\sim 120$ years. Note the difference in scale between pictures on the left-hand panels and others.

ilar to Hayba and Ingebritsen [1994], we use a low ductile permeability at high temperature of $10^{-22} \mathrm{~m}^{2}$. We use a high permeability of $10^{-13} \mathrm{~m}^{2}$ at low temperature which is in agreement with available borehole packer measurements of the shallow oceanic crust [Fisher, 1998]. The associated log linear permeability-temperature functions are plotted in Figure 12 and the heat flux is set to a value of $350 \mathrm{MW} / \mathrm{km}$ of ridge axis. The results show that only when the brittleductile transition is set at the temperature interval from $650^{\circ} \mathrm{C}$ to $750^{\circ} \mathrm{C}$, discharge temperature become higher than $375^{\circ} \mathrm{C}$ (Figure 13). If the brittle-ductile transition is set to a lower temperature interval, then the system cannot remove the heat supplied to the bottom. This results in the formation of a broad hot zone near the bottom, and plumes that can rise at considerable distances away from the axial center. Discharge therefore occurs at many locations on- and off- axis, but temperatures are relatively low. With the brittleductile transition set at $650^{\circ} \mathrm{C}$ to $750^{\circ} \mathrm{C}$, the system can remove the supplied heat, resulting in near-axial discharge areas with temperatures close to $400^{\circ} \mathrm{C}$ (Figure 14).

\section{Mathematical Analysis}

[17] The typical convection style of concentric recharge zones around pipe-like upflow zones, which occurs at high heat flux and permeability, can be understood by analyzing nonlinearity of the fluid properties. Figure 15a shows that heating a fluid from $0^{\circ} \mathrm{C}$ to $\sim 200^{\circ} \mathrm{C}$ will decrease its viscosity by an order of magnitude but will decrease its density by a much smaller fraction (i.e., from $1000 \mathrm{~kg} \mathrm{~m}^{-3}$ to $\sim 900 \mathrm{~kg} \mathrm{~m}^{-3}$ ). As a consequence, $200^{\circ} \mathrm{C}$ fluids can be brought downward very efficiently: the reduced viscosity 


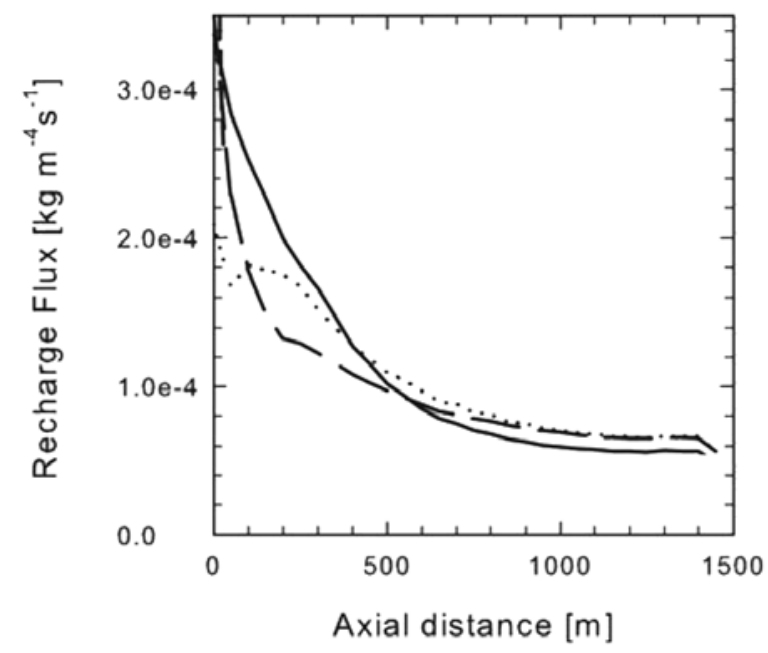

Figure 10. Average recharge $\left(\mathrm{kg} \mathrm{m}^{-2} \mathrm{~s}^{-1}\right)$ versus distance from the axis for heterogeneous permeability models. Using permeability profile 1 (solid line), permeability profile 2 (dashed line), and permeability profile 3 (dotted line).

makes them very mobile and the large density ensures a substantial downward buoyancy force. This behavior can be quantified by writing a simple formula for the vertical mass flux in the axial region:

$$
M_{z}=\rho(T) \mathbf{v}_{z}=\rho(T) \frac{k}{\mu(T)}\left(\frac{\partial p}{\partial z}-\rho(T) \mathbf{g}\right)
$$

where $\partial p / \partial z$ is the vertical pressure gradient in the nearaxial region. The vertical pressure gradient takes a value somewhere between hot and cold hydrostatic such that hot fluids can be transported upward and cold fluids transported downward. Several studies assumed that the pressure gradient is very close to cold hydrostatic [Wilcock and McNabb, 1996; Jupp and Schultz, 2004], based on the idea that discharge zones are much smaller than recharge zones and therefore their resistance would be much higher. The much lower viscosity of the fluid in discharge zones, however, has a counteracting effect, greatly reducing upflow resistance. In the homogeneous permeability simulations, fluids with temperatures of $300^{\circ} \mathrm{C}$ are at neutral buoyancy $\left(\rho_{n}\right)$ in the near-axial region (see Figure 6). This implies, since $\partial p / \partial z=\rho_{n} \mathbf{g}$, that the vertical pressure gradient has a value of $\sim 6000 \mathrm{~Pa} / \mathrm{m}$, roughly halfway in between cold $(\sim 10.000 \mathrm{~Pa} / \mathrm{m})$ and hot $(\sim 3000 \mathrm{~Pa} / \mathrm{m})$ hydrostatic. Figure $15 \mathrm{~d}$ plots $M_{z}$, taking $\partial p / \partial z=6000 \mathrm{~Pa} / \mathrm{m}$, showing that downward mass flux is optimized at $\sim 200^{\circ} \mathrm{C}$ and upward mass flux is optimized at $\sim 400^{\circ} \mathrm{C}$. Analogous to Coumou et al. [2008a], we can derive a simple formula for $\partial p / \partial z$ assuming a pipe model in which recharge occurs in a halo surrounding a pipe-shaped upflow zone:

$$
\frac{\partial p}{\partial z}=\left[\rho_{u}+\left(\rho_{d}-\rho_{u}\right) \frac{1}{\gamma R+1}\right] \mathbf{g} .
$$

Here the geometric constant $\gamma$ is the ratio $A_{u} k_{u} / A_{d} k_{d}$, with $A_{u}$ the cross-sectional area of the upflow zone and $A_{d}$ the cross- sectional area of the downflow zone. $R$ is the ratio of fluid properties $\left(\mu_{d} \rho_{u}\right) /\left(\mu_{u} \rho_{d}\right)$, where subscripts $u$ and $d$ indicate properties in the upwelling and downwelling limb respectively. Physically, the product $\gamma R$ can be seen as the ratio of the hydraulic resistance of the downflow region versus the upflow region. Whenever the resistance in the downflow region increases, compared to the upflow region, $\gamma R$ becomes larger pushing $\partial p / \partial z$ toward hot hydrostatic (i.e., $\left.\rho_{u} \mathbf{g}\right)$. Vice versa, if the resistance in the upflow region increases the pressure gradient is pushed toward cold hydrostatic (i.e., $\rho_{d} \mathbf{g}$ ). Equation (4) assumes that the pressure gradient in the upflow zone is the same as in the near-axial downflow zone. This assumption can be made since in this region fluid flow is dominantly vertical and horizontal pressure gradients are therefore negligible. We define the total heat output of the system as $Q=A_{u}\left(h_{u}-\right.$ $\left.h_{d}\right) M_{z}$, where $h$ is the enthalpy of the fluid. Following Coumou et al. [2008a] we can find an expression for the fluxibility $F$, defined as the ability of a system to transport energy by buoyancy driven convection [Jupp and Schultz, 2004]:

$$
F=\frac{Q}{\mathbf{g} k_{u} A_{u}}=\frac{\rho_{u}\left(h_{u}-h_{d}\right)\left(\rho_{d}-\rho_{u}\right)}{\mu_{u}} \frac{1}{1+\gamma R} .
$$

This expression is an extension of the ordinary definition of fluxibility first defined by Lister [1995], which neglects the resistance in the downflow zone (i.e., $\gamma=0$ ). Here we allow significant resistance in the downflow as well as the upflow zone, resulting in the second term on the right-hand side of equation (5). Figure 15 plots the pressure gradient (b and e) and the heat flux $Q$ (c and f) as functions of the upwelling temperature $T_{u}$ and downwelling temperature $T_{d}$, for $\gamma$ taken as 1 and 3 respectively, and $k=5.0 \times 10^{-14} \mathrm{~m}^{2}$. In both cases, the point of maximum fluxibility coincides with upwelling temperatures of $\sim 400^{\circ} \mathrm{C}$ and downwelling temperatures of $\sim 200^{\circ} \mathrm{C}$. The fluxibility at $\gamma=3$ is substantially lower than at $\gamma=1$, since the resistance of the downflow zone is three times larger. This difference in hydraulic resistance also causes the vertical pressure gradient to be substantially different for different $\gamma$. If $\gamma=1$ the calculated pressure gradient is $\sim 6000 \mathrm{~Pa} / \mathrm{m}$ (Figure 15b), whereas for larger $\gamma$, it drops to smaller values of $\sim 4000 \mathrm{~Pa} / \mathrm{m}$ (Figure 15e). These results have a number of implications which are outlined in the discussion.

\section{Discussion}

\subsection{Maximum Energy Transport}

[18] Based on the simulation results, we can make a first order estimate of the value of $\gamma$. Since the bulk of the recharge takes place in the relatively warm near axial region, we choose $A_{d}$ to be the area in between the $100^{\circ} \mathrm{C}$ and $300^{\circ} \mathrm{C}$ isotherms at a depth of $500 \mathrm{~m} . A_{u}$ is taken as the area for which the temperature is larger than $300^{\circ} \mathrm{C}$ at the same depth. For the homogeneous permeability simulations these areas are roughly the same and hence $\gamma$ is likely to be close to 1 . The systems fluxibility maximizes at $T_{u} \approx 400^{\circ} \mathrm{C}$ and $T_{d} \approx 200^{\circ} \mathrm{C}$ (Figure $15 \mathrm{c}$ ) accompanied with a pressure gradient of $\partial p / \partial z \approx 6000 \mathrm{~Pa} / \mathrm{m}$. These values are very similar to what we observe in our homogenous permeability simulations. This suggests that fluid flow patterns evolve to 

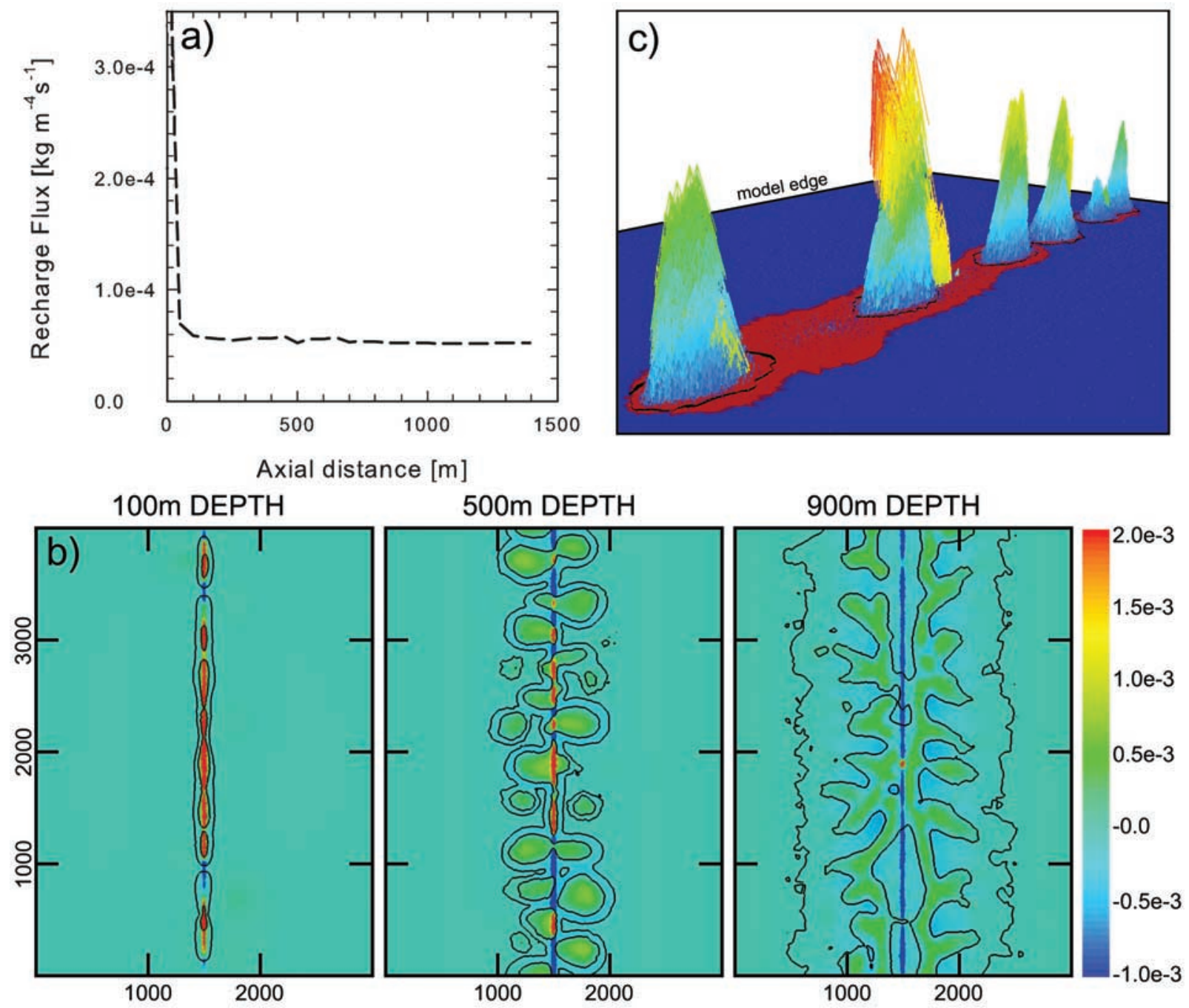

Figure 11. Immature convective flow pattern at early simulation times (50 years) using permeability profile 3 (Figure 7). (a) Recharge through the top boundary (i.e., seafloor), (b) vertical mass fluxes at 100-m, 500-m, and 900-m horizontal slices through the model, (c) volumetric discharge through the top boundary. In Figure 11c, the blue areas are recharge areas and red areas are discharge areas. Large colored structures indicate areas of vigorous discharge, where the height of the structures is a measure for the volume flux through the top surface. The black line is the $100^{\circ} \mathrm{C}$ isotherm.

a state in which the transport of energy is maximized. Upflow in circular, pipe-like zones efficiently heats the surrounding downflowing water, and thereby maximizes mass and energy transport through the system. Previous studies showed that vent temperatures of $\sim 400^{\circ} \mathrm{C}$ indicate that black-smoker hydrothermal systems could be in a state of maximum energy transport [Jupp and Schultz, 2000, 2004]. Our analysis supports this idea and shows that convection cells organize themselves such that downflow zones can be heated efficiently such that mass fluxes and therefore energy fluxes can be maximized.

[19] Due to the presence of salt in oceanic water fluids can phase-separate at pressures typically encountered at black-smoker systems. The effect of two-phase flow on the analysis discussed here is however likely to be small. In our analysis, the properties of the downflowing fluid at temperatures around $\sim 200^{\circ} \mathrm{C}$ are critical and these are only slightly affected when using salt water instead of pure water properties [Driesner and Heinrich, 2007; Driesner, 2007]. Recent two-dimensional saltwater simulations showed that for most parameter settings, two-phase areas will be limited to near magmatic regions and hence the structure of the convective cell is not affected [Coumou et al., 2009]. Only with shallow ocean depths $(\sim 1500 \mathrm{~m})$ are two-phase upflow zones likely to form but since areas of countercurrent flow are limited they are also not likely to have a strong effect on three-dimensional cell structure [Coumou et al., 2009].

\subsection{Permeability Heterogeneity}

[20] For the heterogeneous permeability case, the use of formulas (4) and (5) is less straightforward, but can still provide some useful insights. We estimate $A_{u}$ and $A_{d}$ in the same way as for the homogeneous permeability case, giving, in a first order approximation, that $A_{u} / A_{d} \sim 1$ and hence $\gamma$ scales with $k_{u} / k_{d}$. Increasing the permeability in the upflow region, therefore pushes the vertical pressure gradi- 


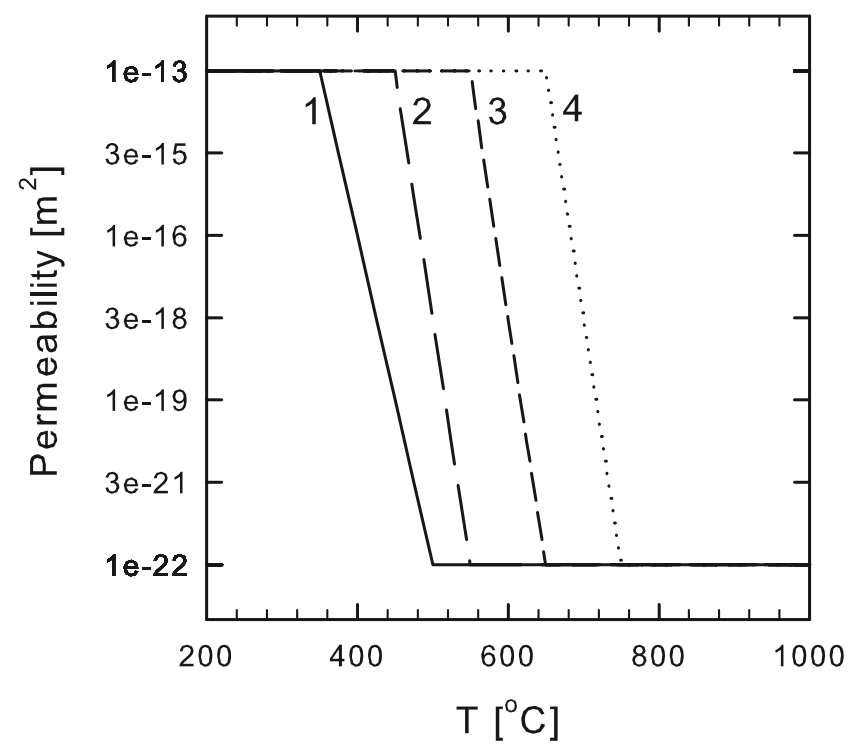

Figure 12. Investigated temperature-dependent permeability models $k(T)$.

ent toward hot hydrostatic, since $\gamma>1$. For $\gamma=3$, the peak in fluxibility is still at the same upwelling and downwelling temperatures, but the pressure gradient is much smaller, i.e., $\sim 4000 \mathrm{~Pa} / \mathrm{m}$. This value, however, should be treated with care since the assumption that horizontal pressure gradients in the near axial region are close to zero could be violated at such low vertical pressure gradients. Nevertheless, heterogeneous permeability systems still operate at upwelling temperatures of $\sim 400^{\circ} \mathrm{C}$ and the bulk of the downflow has temperature of $\sim 200^{\circ} \mathrm{C}$, as confirmed by the simulations, and pressure gradients in the near-axial region decrease due to the low hydraulic resistance of the upflow zone. Geologic evidence suggests that upflow zones are naturally drawn to high-permeability fault zones [Hayman and Karson, 2007, 2009] as also seen in our simulations. If this is true, than the pressure gradient in upflow regions is likely to be closer to hot hydrostatic rather than cold hydrostatic, as often has been assumed [Jupp and Schultz, 2000, 2004; Lowell and Germanovich, 2005].

\subsection{Diffuse Venting}

[21] In the previous sections we showed that optimal energy transport is achieved in a pipe-like upflow region with concentric zones of relatively warm downflowing fluids. This state, however, is only achieved when convection is fully developed, which can take many years. Before that, in the initialization phase, we observed a diffusive venting style in our simulations, with relatively low-temperature fluids venting in regions connecting high-temperature "blacksmoker" style vent fields. Again, formula (4) can provide some understanding of what is causing this phenomenon. During initial plume formation, downflow zones are still essentially at ambient seawater temperatures, since regions surrounding upflow zones have not heated up yet. At this point, the hydraulic resistance of downflow is large due to the high viscosity at ambient temperatures. Therefore the pressure gradient will settle at a value close to hot hydro- static (see also Figure 15e) to drive the required downflow to the base of the hydrothermal system. Such a lowpressure gradient implies that relatively warm fluids can become neutrally buoyant. Indeed, fluids at the periphery of upflow regions, which lose heat by diffusion and mixing, can easily become neutrally buoyant. Graphically, this is expressed in the steep gradient of the curve in Figure 15d in the range from $350-400^{\circ} \mathrm{C}$ : Even a small temperature drop can decrease the upward buoyancy force substantially. Consequently, fluids in the periphery of upflow zones can lose their upward buoyancy force, which is expressed as low-velocity, diffusive-style venting at the seafloor. This phenomenon was in particular observed in simulations with an increased axial permeability. In these simulations, rising thermal plumes preferentially take flow paths in the highpermeable zone, whereas downflow is mainly restricted to the lower permeable regions. This affects the relative resistance between up- and downflow zones, pushing the pressure gradient even more toward hot hydrostatic. Once convection is fully developed into high-temperature upflow and surrounding, moderate temperature downflow, diffuse venting ceases and only focused black-smoker style venting occurs.

[22] We therefore propose that diffuse vent sites might be an indication for subseafloor convection being recharge dominated and not yet in its state of optimal energy transport. This hypothesis is supported by several observations of natural diffuse vent fields. First, diffuse vent fields are always at lower temperatures and typically found at the periphery of active black-smoker vent fields [Hannington et al., 1995]. Second, diffusive style venting is often observed directly after a dike injection, before the emergence of hightemperature black smokers [Hannington et al., 1995]. A possible explanation is that a magmatic event increases the permeability predominantly in the upflow region and there-

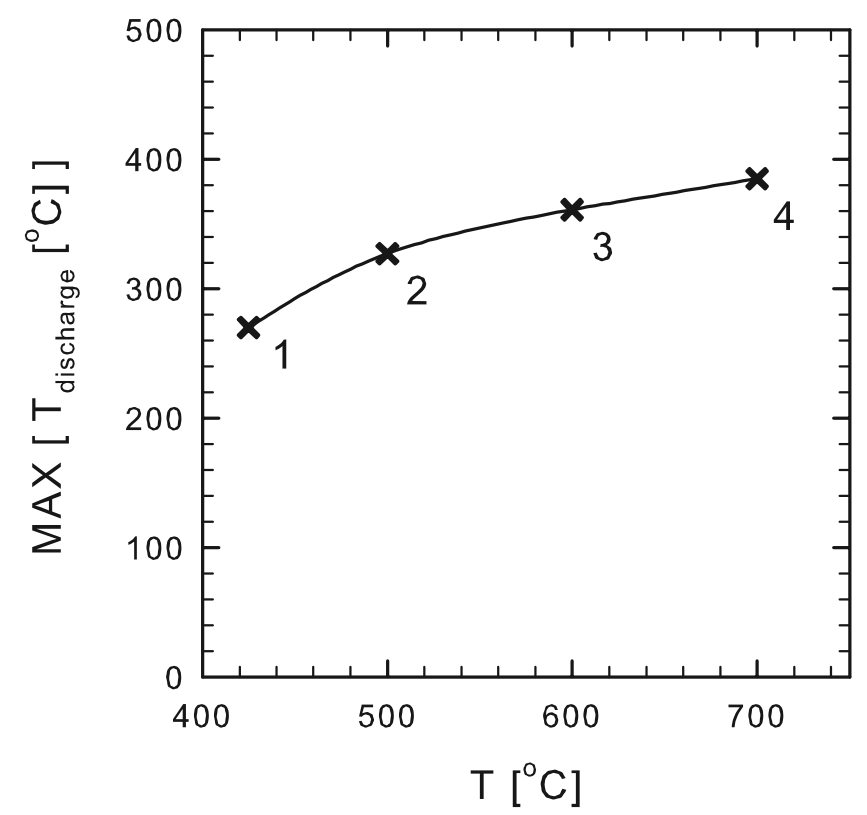

Figure 13. Maximum discharge temperature as a function of temperature-dependent permeability profile. Numbers refer to permeability profiles as defined in Figure 12. 

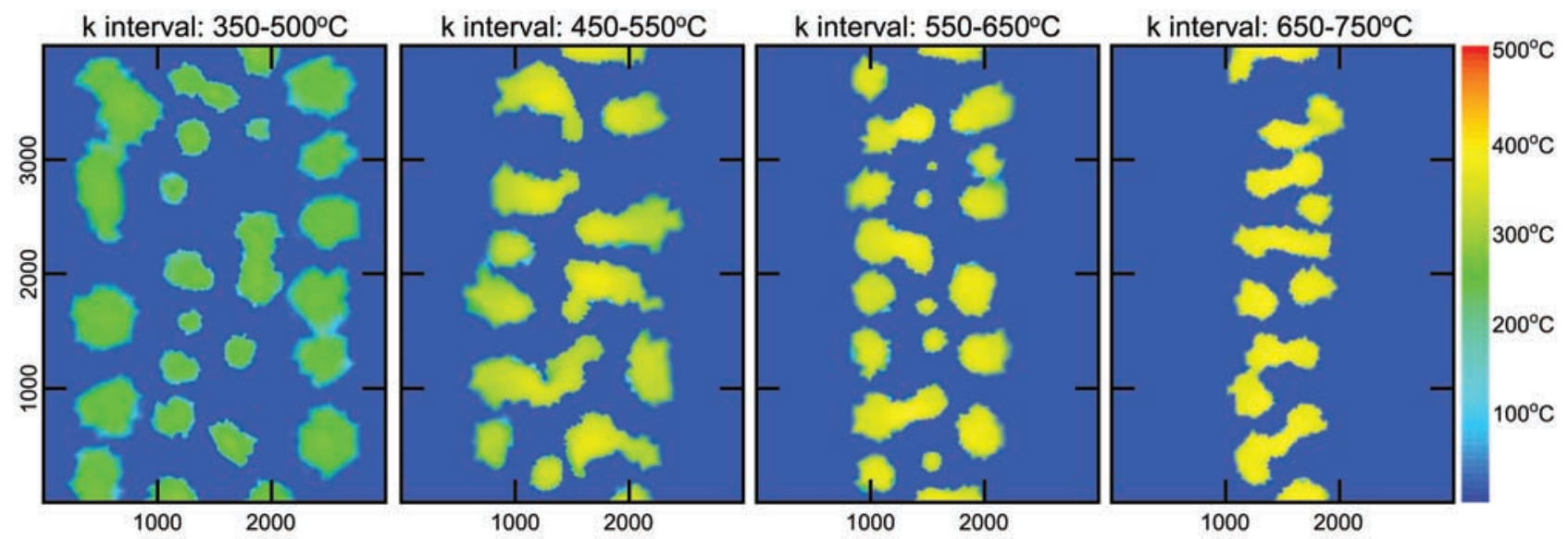

Figure 14. Temperature at the top surface of temperature-dependent permeability simulations, using (a) $k(T)$-function 1, (b) $k(T)$-function 2, (c) $k(T)$-function 3, and (d) $k(T)$-function 4 (see Figure 12).

fore the system becomes recharge dominated. Over time, venting tends to become more and more focused in blacksmoker fields, reflecting the heating of near-axial recharge zones and an accompanying shift of the pressure gradient toward cold hydrostatic. In natural systems, the shift from diffuse style to focused venting has been observed on much smaller timescales than seen in our models. A possible explanation for this is that the permeability after a dyke injection is temporarily much larger than values used in this study.

[23] Wilcock [1998] showed that diffuse type vent fluids can be generated by mixing of a high-temperature hydrothermal fluid with seawater in the high-permeability extrusive layer. Our explanation can in a sense be seen as an extension to this idea: Highly permeable regions, either in the form of a horizontal extrusive layer or a near-vertical
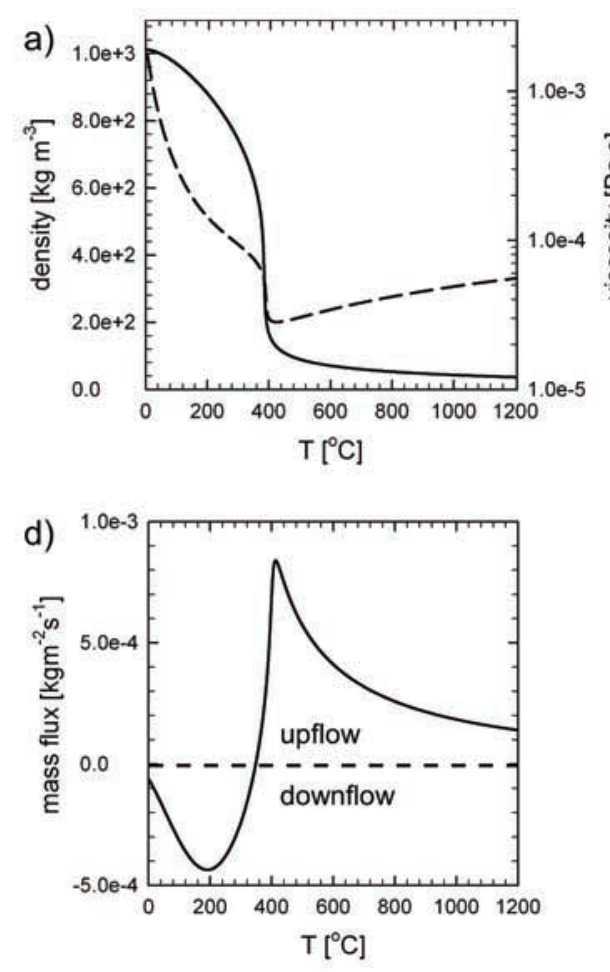
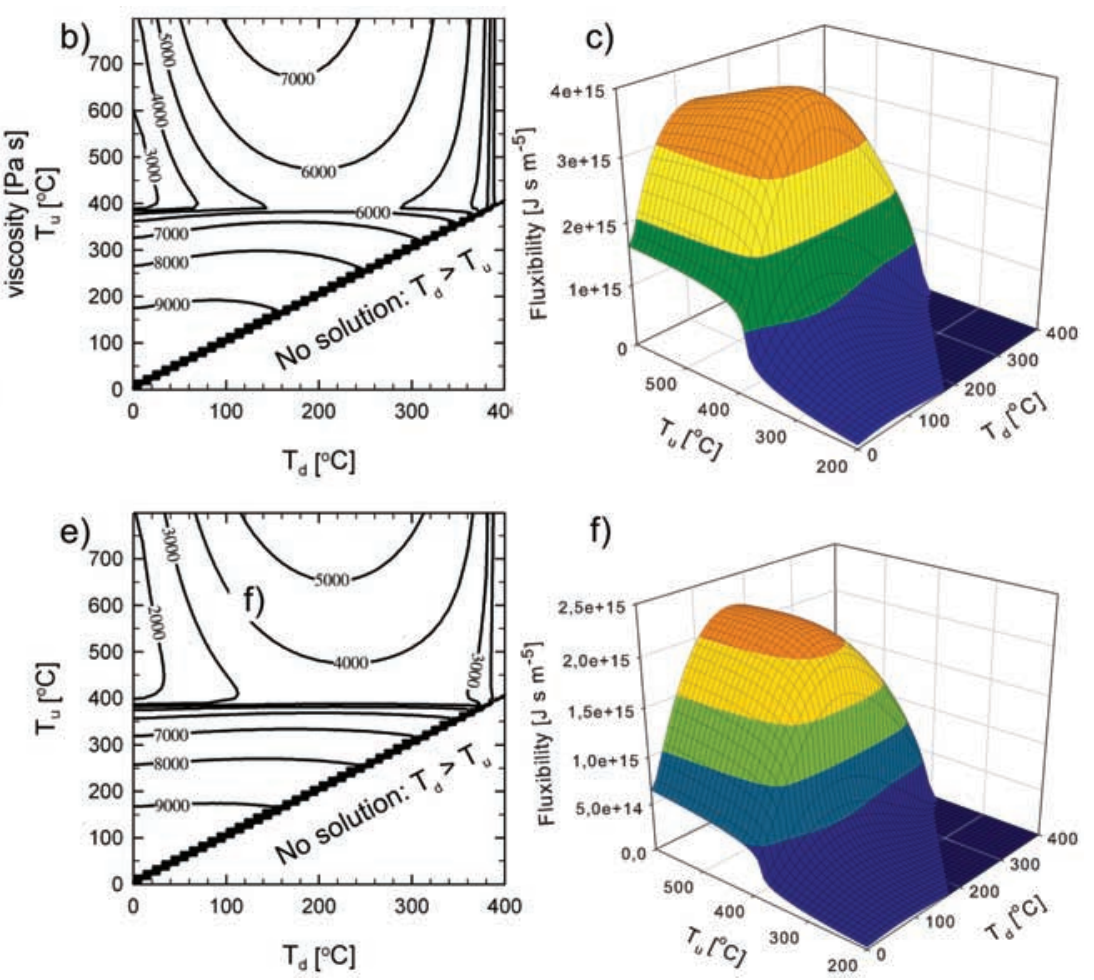

Figure 15. (a) Density (solid line) and viscosity (dashed line) as function of temperature. (b) Vertical pressure gradient (equation 4) as function of upwelling and downwelling temperature, $\gamma=1$. (c) Fluxibility $F$ (equation 5) as function of upwelling and downwelling temperature, $\gamma=1$ and $k=5.0 \times$ $10^{-14} \mathrm{~m}^{2}$. (d) Vertical mass flux (equation 5) as function of temperature. Figures $15 \mathrm{e}$ and $15 \mathrm{f}$ plot the same as Figures $15 \mathrm{~b}$ and $15 \mathrm{c}$, respectively, with $\gamma=3$. For generation of all of these plots, a pressure of $25 \mathrm{MPa}$ was used. 
fault zone, are likely to lead to diffusive style venting at the seafloor.

\subsection{Permeability}

[24] We constrained the permeability by fitting bottom temperatures to expected temperatures of magmatic melt lenses. We find values for $k$ ranging from $0.75 \times 10^{-14}$ $5 \times 10^{-14} \mathrm{~m}^{2}$, using heat fluxes of respectively $75 \mathrm{MW} / \mathrm{km}$ and $350 \mathrm{MW} / \mathrm{km}$, which are at the lower range of axial permeability estimates from previous studies [Lowell and Germanovich, 1994; Wilcock and McNabb, 1996; Fisher, 1998; Lowell and Germanovich, 2005]. The approach, however, has an important limitation. It assumes that the boundary layer between the magma lens and the hydrothermal system is in a thermal steady state, i.e., the amount of heat coming from the magma chamber is removed by the hydrothermal system but the magma lens itself is not cooled, remaining at temperatures around $1200^{\circ} \mathrm{C}$. Though plausible, such a balance is by no means required in nature. In fact, measurements indicate that some hydrothermal systems remove heat at a faster rate than can be delivered by the oceanic crustal accretion process [Baker and Massoth, 1987; Ginster et al., 1994; Baker and Urabe, 1996; Ramondenc et al., 2006]. This could mean that the magma lens cools and the hydrothermal cell pushes the magma lens down by means of thermal cracking fronts [Lister, 1974]. If this is the case, our permeability estimates should be seen as a lower limit for the heat fluxes used.

[25] The simulations with a temperature-dependent permeability show, for this specific model geometry and boundary conditions, that if the brittle-ductile transition is at relatively low temperatures then the systems cannot remove the supplied heat. If the brittle-ductile transition is set from $650^{\circ} \mathrm{C}$ to $750^{\circ} \mathrm{C}$, then the seafloor expression, in terms of location of vent fields and venting temperature matches much better with observations. This estimate of the brittle-ductile transition at $700^{\circ} \mathrm{C}$ centers in between recent estimates based on the occurrence of earthquakes in oceanic crust $\left(600^{\circ} \mathrm{C}\right.$ [McKenzie et al., 2005]) and those from rheologic calculations $\left(700-800^{\circ} \mathrm{C}\right.$ [Hirth et al., 1998]).

\subsection{Vent Field Distribution}

[26] One key observation at mid-ocean ridges is that venting is focused in black-smoker fields separated from each other by stretches of unaffected seafloor. In our lowheat flux simulations, an axial plane with increased permeability is required to produce such discrete vent fields. Though no strict slot convection mode develops, fluid flow patterns are dominantly in the high-permeability axial plane. Without a high-permeability plane, fluid flow in low heat flux systems is mainly across-axis and venting occurs everywhere along the axial center, in contradiction with observations. Further, at a heat flux of $75 \mathrm{MW} / \mathrm{km}$ maximum vent temperatures are substantially lower than typically observed (only $300^{\circ} \mathrm{C}$ ), which indicates that the heat fluxes at active systems are likely larger and that a heat flux of $75 \mathrm{MW} / \mathrm{km}$ is probably more representative of a dying system.

[27] The high heat flux models $(350 \mathrm{MW} / \mathrm{km})$ give a better match with observations at natural systems, both in terms of vent temperature and in terms of vent field spacing. In particular, they do not require a high-permeability axial plain to produce separate vent fields. Instead, for a homogeneous permeability, convection organizes itself in circular, pipe-like upflow regions surrounded by regions of increased downflow. Increasing the permeability in a narrow zone at the axial center does not affect this convective behavior significantly. For the moderate permeability contrasts tested in this study, this pipe-like flow structure remains dominant. Only at an early stage of convection does the permeability contrast strongly influence fluid flow patterns with rising fluid dominating in the high-permeable regions. Downflow zones have not heated up yet in this immature convective stage and hence the permeability structure dominates fluid patterns rather than the fluid properties. In our tested heterogeneous permeability scenarios this resulted in elongated vent fields which stretch over most of the axial center with only small localized recharge areas. Continued circulation heats up the surrounding downflow zones and the influence of fluid properties becomes the controlling factor, creating a pipe-like flow structure. Further simulations with sharper permeability contrasts are required to test the generality of this conclusion. Also, more realistic permeability scenarios like highly permeable extrusive and/or steeply dipping normal faults need to be tested in three dimensions.

\subsection{Field Evidence}

[28] Substantial evidence exists in nature for pipe-like convective systems, as observed in our simulations. Tivey and Johnson [2002] gathered magnetic anomaly data from the Endeavour segment of the Juan de Fuca Ridge to infer the subseafloor structure of upflow regions. They observe circular magnetic lows at active and inactive venting areas, which look remarkably similar to the thermal structure at the top of homogenous permeability models. Tivey and Johnson [2002] interpret these subseafloor structure as near-vertical pipe-like source regions, in agreement with our results. Further evidence for focused, pipe-like upflow regions comes from ophiolites [Saccocia and Gillis, 1995; Juteau et al., 2002].

[29] An additional feature of pipe-like upflow observed in our simulations is the existence of halos of increased downwelling surrounding the upflow zones. Recharge regions therefore might be less extensive than previously thought. In our homogeneous permeability simulations, $\sim 2 / 3$ of the downward mass flux at middepth occurs within $\sim 500 \mathrm{~m}$ of the axis. Temperatures within these "focused recharge" zones are substantially higher than often assumed for recharge regions, but are in agreement with results from recent two-dimensional simulations [Fontaine and Wilcock, 2007]. They are also compatible with temperature distributions inferred from the study of mineral assemblages at different levels in oceanic crust [Alt, 1995]. Coogan [2008] shows that metamorphic temperatures in sheeted dykes range from $100^{\circ} \mathrm{C}$ to $400^{\circ} \mathrm{C}$ [Coogan, 2008, Figure 2] and argues that such relatively high temperatures are incompatible with the standard model of hydrothermal convection in which fluid reacts with rock dominantly within the broad, cold downflow regions. Coogan [2008] therefore suggests that, assuming downflow is cold, fluid rock reaction largely occurs as fluid migrates upward. Our simulations show that efficient fluid-rock reaction at temperatures higher than $100^{\circ} \mathrm{C}$ will occur in a wide $(\sim 1 \mathrm{~km})$ region in both up- 
(more than $300^{\circ} \mathrm{C}$ ) and downflow (less than $300^{\circ} \mathrm{C}$ ) zones, which seems compatible with measured metamorphic temperatures.

[30] To draw these relatively warm fluids down, the pressure gradient needs to be sufficiently low (i.e., $\sim 6000 \mathrm{~Pa} / \mathrm{m})$. No direct pressure data exist from blacksmoker upflow zones, but boreholes from geothermal systems reveal pressure gradients roughly midway between hot and cold hydrostatic [Grant et al., 1984]. Finally, recent seismic data from the East Pacific Rise $9^{\circ} 50^{\prime} \mathrm{N}$ indicate that recharge can indeed occur focused and very close to the axis, directly above the magmatic melt lens [Tolstoy et al., 2008].

\section{Conclusions}

[31] We report high-resolution three-dimensional simulations of thermal convection at mid-ocean ridges, including the full nonlinearity of the properties of supercritical $\mathrm{H}_{2} \mathrm{O}$. The simulations show that pipe-like upflow, observed in several natural systems, forms naturally at sufficiently high heat flux and permeability. This style of convection is accompanied by halos of increased downflow surrounding upflow regions. As a result of the nonlinear dependence of the viscosity, density and heat capacity of the fluid on temperature and pressure, the systems' heat output is maximized for this configuration. Venting occurs in circular high-temperature regions separated from each other by recharge areas, even when the permeability is homogeneous. Therefore slot convection, in which convection is dominantly two-dimensional within a high-permeability axial plane, is not required to explain separately spaced vent fields in nature. In fact, an increased axial permeability causes vent fields to become elongated and connected with one another and thereby less resemble the typical distribution of natural vent fields. In such high axial permeability simulations, the pressure gradient can approach hot hydrostatic values during the early stages of convection, causing rather warm fluids to become near neutrally buoyant. Based on this mechanism, we propose a new hypothesis to explain diffuse venting at the edges of black-smoker fields and after dike injections.

[32] Acknowledgments. We thank reviewers William Wilcock and John Maclennan, as well as Wim van Westrenen as associate editor, for their useful comments that have substantially improved the quality of the manuscript. This work was supported by the Swiss National Science Foundation grant 200020-107955.

\section{References}

Alt, J. (1995), Subseafloor processes in mid-ocean ridge hydrothermal systems, in Seafloor Hydrothermal Systems, Geophys. Monogr., vol. 91, edited by S. E. Humphris et al., pp. 85-114, AGU, Washington, D. C.

Baker, E., and G. Massoth (1987), Characteristics of hydrothermal plumes from two vent fields on the Juan de Fuca Ridge, northeast Pacific Ocean, Earth Planet. Sci. Lett., 85, 59-73.

Baker, E., and T. Urabe (1996), Extensive distribution of hydrothermal plumes along the superfast spreading East Pacific Rise $13^{\circ} 30^{\prime}-$ $18^{\circ} 40^{\prime}$ S, J. Geophys. Res., 101(B4), 8685-8695.

Bear, J. (1972), Dynamics of Fluids in Porous Media, Dover, New York.

Cherkaoui, A., and W. Wilcock (1999), Characteristics of high Rayleigh number two-dimensional convection in an open-top porous layer heated from below, J. Fluid Mech., 394, 241-260.

Coogan, L. (2008), Reconciling temperatures of metamorphism, fluid fluxes, and heat transport in the upper crust at intermediate to fast spreading mid-ocean ridges, Geochem. Geophys. Geosyst., 9, Q02013, doi:10.1029/2007GC001787.
Coumou, D., T. Driesner, S. Geiger, C. Heinrich, and S. Matthai (2006), The dynamics of mid-ocean ridge hydrothermal systems: Splitting plumes and fluctuating vent temperatures, Earth Planet. Sci. Lett., 245, $218-231$.

Coumou, D., T. Driesner, and C. Heinrich (2008a), The structure and dynamics of mid-ocean ridge hydrothermal systems, Science, 321, 1825-1828.

Coumou, D., T. Driesner, and C. Heinrich (2008b), Heat transport at boiling, near critical conditions, Geofluids, 8, 208-215.

Coumou, D., S. Matthai, S. Geiger, and T. Driesner (2008c), A parallel FE-FV scheme to solve fluid flow in complex geologic media, Comp. Geosci., 34, 1697-1707.

Coumou, D., T. Driesner, P. Weis, and C. Heinrich (2009), Phase separation, brine formation and salinity variation at black smoker hydrothermal systems, J. Geophys. Res., 114, B03212, doi:10.1029/2008JB005764.

Driesner, T. (2007), The system $\mathrm{H}_{2} \mathrm{O}-\mathrm{NaCl}$. Part II: Correlations for molar volume, enthalpy, and isobaric heat capacity from 0 to $1000^{\circ} \mathrm{C}, 0$ to 5000 bar, and 0 to $1 \mathrm{x}_{\mathrm{NaCl}}$, Geochim. Cosmochim. Acta, 71, 4902-4919.

Driesner, T., and C. Heinrich (2007), The system $\mathrm{H}_{2} \mathrm{O}-\mathrm{NaCl}$. Part I: Correlation formulae for phase relations in temperature-pressure-composition space from 0 to $1000^{\circ} \mathrm{C}, 0$ to 5000 bar, and 0 to $1 \mathrm{x}_{\mathrm{NaCl}}$, Geochim. Cosmochim. Acta, 71, 4880-4901.

Dunn, R., D. Toomey, and S. Solomon (2000), Three-dimensional seismic structure and physical properties of the crust and shallow mantle beneath the East Pacific Rise at $9^{\circ} 30^{\prime} \mathrm{N}$, J. Geophys. Res., 105(B10), 23,537-23,556

Fisher, A. (1998), Permeability within basaltic oceanic crust, Rev. Geophys., $36(2), 143-182$

Fisher, A. (2001), Geophysical constraints on hydrothermal circulation, in Energy and Mass Transfer in Marine Hydrothermal Systems, Dahlem Workshop Report, vol. 89, edited by P. E. Halbach, V. Tunnicliffe, and J. R. Hein, pp. 29-52, Dahlem Univ. Press.

Fontaine, F., and W. Wilcock (2007), Two-dimensional numerical models of open-top hydrothermal convection at high rayleigh and nusselt numbers: Implications for mid-ocean ridge hydrothermal circulation, Geochem. Geophys. Geosyst., 8, Q07010, doi:10.1029/2007GC001601.

Geiger, S. (2004), Numerical simulation of the hydrodynamics and thermodynamics of $\mathrm{NaCl}^{-} \mathrm{H}_{2} \mathrm{O}$ fluids, Ph.D. thesis, ETH Zurich, Switzerland.

Geiger, S., S. Roberts, S. Matthai, C. Zoppou, and A. Burri (2004), Combining finite element and finite volume methods for efficient multiphase flow simulations in highly heterogeneous and structurally complex geologic media, Geofluids, 4, 284-299.

Geiger, S., T. Driesner, C. Heinrich, and S. Matthai (2006), Multiphase thermohaline convection in the Earth's crust: I. A novel finite elementfinite volume solution technique combined with a new equation of state for $\mathrm{NaCl}-\mathrm{H}_{2} \mathrm{O}$, Transp. Porous Media, 63, 399-434.

Ginster, U., M. Mottl, and R. Von Herzen (1994), Heat flux from black smokers on the Endeavour and Cleft segments, Juan de Fuca Ridge, J. Geophys. Res., 99(B3), 4937-4950.

Grant, M., I. Donaldson, and P. Bixley (1984), Geothermal Reservoir Engineering, Hemisphere, Washington, D. C.

Haar, L., J. S. Gallagher, and G. S. Kell (1982), NBS/NRC Steam Tables, Academic, London.

Hannington, M., I. Jonasson, P. Herzig, and S. Petersen (1995), Physical and chemical processes of seafloor mineralization at mid-ocean ridges, in Seafloor Hydrothermal Systems: Physical, Chemical, Biological and Geological Interactions, Geophys. Monogr., vol. 91, edited by E. Humphris et al., pp. 115-157, AGU, Washington, D. C.

Hayba, D. O., and S. Ingebritsen (1994), Multiphase groundwater flow near cooling plutons, J. Geophys. Res., 102(B6), 12,235-12,252.

Hayman, N., and J. Karson (2007), Faults and damage zones in fast-spread crust exposed on the north wall of the Hess Deep Rift: Conduits and seals in seafloor hydrothermal systems., Geochem. Geophys. Geosyst., 8, Q10002, doi:10.1029/2007GC001623.

Hayman, N., and J. Karson (2009), Crustal faults exposed in the Pito Deep Rift: Conduits for hydrothermal fluids on the southeast Pacific Rise, Geochem. Geophys. Geosyst., 10, Q02013, doi:10.1029/2008GC002319.

Hirth, G., J. Escartn, and J. Lin (1998), The rheology of the lower oceanic crust: Implications for lithospheric deformation at mid-ocean ridges, in Faulting and Magmatism at Mid-Ocean Ridges, Geophys. Monogr., vol. 106, edited by W. R. Buck et al., pp. 291-304, AGU, Washington, D. C.

Ingebritsen, S., and D. O. Hayba (1994), Fluid flow and heat transport near the critical point of $\mathrm{H}_{2} \mathrm{O}$, Geophys. Res. Lett., 21(20), 2199-2202.

Jupp, T., and A. Schultz (2000), A thermodynamic explanation for blacksmoker temperatures, Nature, 403(6772), 880-883.

Jupp, T., and A. Schultz (2004), Physical balances in subseafloor hydrothermal convection cells, J. Geophys. Res., 109, B05101, doi:10.1029/ 2003JB002697.

Juteau, T., G. Manac, O. Moreau, C. Lcuyer, and C. Ramboz (2002), The high temperature reaction zone of the Oman ophiolite: New field data, 
microthermometry of fluid inclusions, PIXE analyses and oxygen isotopic ratios, Mar. Geophys. Res., 21(3-4), 351-385.

Kent, G., et al. (2000), Evidence from three-dimensional seismic reflectivity images for enhanced melt supply beneath mid-ocean-ridge discontinuities, Nature, 406, 614-618.

Lister, C. (1974), On the penetration of water into hot rock, Geophys. J. R. Astron. Soc., 39, 465-509.

Lister, C. (1995), Heat transfer between magmas and hydrothermal systems, or, six lemmas in search of a theorem, Geophys. J. Int., 120, 45-59.

Lowell, R., and L. Germanovich (1994), On the temporal evolution of hightemperature hydrothermal systems at ocean ridge crests., J. Geophys. Res., 99(B1), 565-575.

Lowell, R., and L. Germanovich (2005), Hydrothermal processes at midocean ridges: Results from scale analysis and single-pass models, in MidOcean Ridges: Hydrothermal Interactions Between the Lithosphere and Oceans, Geophys. Monogr., vol. 148, edited by C. R. German, J. Lin, and L. M. Parson, pp. 219-244

Lowell, R., A. Rona, and R. Von Herzen (1995), Seafloor hydrothermal systems, J. Geophys. Res., 10(B1), 327-352.

McKenzie, D., J. Jackson, and K. Priestley (2005), Thermal structure of oceanic and continental lithosphere, Earth Planet. Sci. Lett., 233 , $337-349$

Paluszny, A., S. Matthai, and M. Hohmeyer (2007), Hybrid finite elementfinite volume discretization of complex geologic structures and a new simulation workflow demonstrated on fractured rocks, Geofluids, 7, $1-23$.

Rabinowicz, M., J. Boulègue, and P. Genthon (1998), Two- and threedimensional modeling of hydrothermal convection in the sedimented Middle Valley segment, Juan de Fuca Ridge, J. Geophys. Res., 103(B10), 24,045-24,065.

Rabinowicz, M., J.-C. Sempéré, and P. Genthon (1999), Thermal convection in a vertical permeable slot: Implications for hydrothermal circulation along mid-ocean ridges, J. Geophys. Res., 104(B12), 29,275-29,292.

Ramondenc, P., L. Germanovich, K. Von Damm, and R. Lowell (2006), The first measurements of hydrothermal heat output at $9^{\circ} 50^{\prime} \mathrm{N}$, East Pacific Rise, Earth Planet. Sci. Lett., 245(3-4), 487-497.

Rosenberg, N., F. Spera, and R. Haymon (1993), The relationship between flow and permeability field in seafloor hydrothermal systems, Earth Planet. Sci. Lett., 116, 135-153.
Saccocia, P., and K. Gillis (1995), Hydrothermal upflow zones in the oceanic crust, Earth Planet. Sci. Lett., 136(1-2), 1-16.

Schoofs, S., and U. Hansen (2000), Depletion of a brine layer at the base of the ridge-crest hydrothermal system, Earth Planet. Sci. Lett., 180(3-4), $341-353$.

Singh, S., G. Kent, J. Collier, A. J. Harding, and J. Orcutt (1998), Melt tomush variations in crustal magma properties along the ridge crest at the southern East Pacific Rise, Nature, 394, 874-878.

Sinton, J., and R. Detrick (1992), Mid-ocean ridge magma chamber, J. Geophys. Res., 97(B1), 197-216.

Straus, J., and G. Schubert (1977), Thermal convection of water in a porous medium: Effects of temperature and pressure-dependent thermodynamic and transport properties, J. Geophys. Res., 82(2), 325-332.

Tivey, M., and H. Johnson (2002), Crustal magnetization reveals subsurface structure of Juan de Fuca Ridge hydrothermal vent fields, Geology., 30(11), 979-982.

Tolstoy, M., F. Waldhause, D. Bohnenstiehl, R. Weekly, and W. Kim (2008), Seismic identification of along-axis hydrothermal flow on the East Pacific Rise, Nature, 451, 181-185.

Travis, B., D. Janecky, and N. Rosenberg (1991), Three-dimensional simulation of hydrothermal circulation at mid-ocean ridges, Geophys. Res. Lett., 18(8), 1441-1444.

Von Damm, K., M. Lilley, W. Shanks, M. Brockington, A. Bray, K. O’Grady, E. Olson, A. Graham, G. Proskurowski, and the SouEPR Science Party (2003), Extraordinary phase separation and segregation in vent fluids from the southern East Pacific Rise, Earth Planet. Sci. Lett., 206, 365-378.

Wilcock, W. S. D. (1998), Cellular convection models of mid-ocean ridge hydrothermal circulation and the temperatures of black smoker fluids, J. Geophys. Res., 103(B2), 2585-2596.

Wilcock, W. S. D., and A. McNabb (1996), Estimates of crustal permeability on the Endeavour segment of the Juan de Fuca mid-ocean ridge, Earth Planet. Sci. Lett., 138, 83-91.

D. Coumou, T. Driesner, and C. A. Heinrich, Department of Earth Sciences, Institute of Isotope Geochemistry and Mineral Resources, ETH Zurich, Clausiusstrasse 25, CH-8092 Zurich, Switzerland. (coumou@erdw. ethz.ch)

S. Geiger, Institute of Petroleum Engineering, Heriot-Watt University, Riccarton Campus, Edinburgh EH14 4AS, UK.

A. Paluszny, Department of Earth Science and Engineering, Imperial College London, RSM Building, Exhibition Road, London SW7 2AZ, UK 